\title{
Measuring turbine inflow with vertically-profiling lidar in complex terrain
}

Wharton, S. ${ }^{1, *}$, Newman, J.F. ${ }^{2}$, Qualley, G. ${ }^{3, \dagger}$, Miller, W.O. ${ }^{4}$

${ }^{1}$ Atmospheric, Earth and Energy Division, Lawrence Livermore National Laboratory, 7000 East Avenue, L-103, Livermore, California, USA, 94550; wharton4@1lnl.gov

${ }^{2}$ School of Meteorology, University of Oklahoma, 120 David L. Boren Blvd., Norman, Oklahoma, USA, 73072; jennifer.newman@ou.edu

${ }^{3}$ Infigen Energy, 5307 E. Mockingbird Lane, Dallas, Texas, USA, 75206

${ }^{4}$ Computational Engineering Division, Lawrence Livermore National Laboratory, 7000 East Avenue, L-103, Livermore, California, USA, 94550; miller99@1lnl.gov

*Author to whom correspondence should be addressed: wharton4@llnl.gov; Tel.: +1-925-4229295; Fax: +1-925-423-4908

†Present address: Pentalum-The Americas, 1808 Industrial Blvd., Suite 300, Colleyville, Texas, USA, 76034; Grant.Qualley@pentalum.com

Keywords: complex terrain, Altamont Pass, wind resource, wind power, lidar, hill "speed-up", inflow, wind shear

\section{Abstract}

Two Laser and Detection Ranging (lidar) units were deployed in the Altamont Pass region of California to study complex flow dynamics at a moderately complex terrain wind farm. The lidars provided wind measurements at the base and along the slope of a $140 \mathrm{~m}$ tall ridge and captured air flow as it moved up and along the ridge towards an unwaked turbine under varying 
stability conditions. Elevation enhanced wind speed during well-mixed or near-neutral conditions at the top of the ridge; however, the hill "speed-up" was smaller than expected during stable conditions. At these times the upwind terrain played a significant role in local flow variability as did terrain features within the wind farm. The observations were next analyzed to assess the ability of using vertically-profiling lidar in complex terrain to measure free-stream inflow for evaluating power generation response. Better agreement between the lidar wind speed and expected power was found once the lidar measurements had been adjusted for stabilitydependent hill speed-up effects. This suggests that vertically-profiling lidar can be used in complex terrain to measure inflow if the terrain-induced flow features are also considered.

\section{Introduction}

Wind farm estimations of the local wind resource and evaluations of turbine power performance are largely based on methodologies prescribed by the International Electrotechnical Commission (IEC) 61400-12-1 Standard (IEC 2007). These standards require that free-stream wind measurements, used for turbine siting and generating measured power curves, be made using calibrated cup anemometers on an upwind meteorological tower. To date, there is no formal recommendation by the IEC regarding the alternative use of remote sensing devices such as laser detection and ranging (lidar) or sound detection and ranging (sodar) instruments for measuring the free-stream wind. Yet, these systems have some advantages over traditional meteorological towers, including their ease of mobility and ability to measure multiple flow characteristics (e.g., shear, veer, velocity, turbulence) across the full turbine rotor-disk profile. In attempts to fill this void the International Energy Agency (IEA) Wind Task Group Expert Group recently published a guide of recommended practices for ground-based, vertically-profiling remote sensing systems 
for wind resource assessment (IEA 2013). The guide provides recommendations on installing, operating, and processing lidar data to produce accurate measurements of wind speed and direction with remote sensing instruments. It also stresses the need for additional field studies, particularly in complex terrain, to better quantify the limitations of using lidar to measure freestream wind flow at wind farms.

Wind turbines are frequently sited along the crest of hills or ridgelines to take advantage of terrain-enhanced flows. While complex terrain can favor increased wind speeds, it also can cause uncertainty in the expected wind field as the wind profile no longer follows the classical logarithmic wind speed profile (e.g., Panofsky and Ming 1983, Kaimal and Finnigan 1994). The effect of terrain also makes it difficult to predict turbine power generation based on observed wind conditions; it becomes increasingly hard to accurately measure the free-stream flow or "inflow" into the turbine as the topography becomes more complex. The IEC 61400-12-1 Standard recommends that wind measurements be taken 2-4 rotor disk lengths in front of a turbine to capture un-obstructed, free-stream inflow (IEC 2007). In flat homogenous terrain, these measurements are likely a close representation of the actual wind conditions experienced by the turbine; however, in complex terrain this is no longer true as changes in terrain and surface roughness alter the flow's mean wind speed, direction and scales of turbulence.

Here, we present high-resolution, multiple lidar observations from a wind farm in the Altamont Pass Wind Region of California, USA for the purposes of measuring the free-stream wind flow, including any changes in wind speed, direction and turbulence as air moved up and along an elongated ridge towards an unwaked turbine. In addition, we quantitatively assess the use of lidar 
wind speed measurements in complex terrain for providing inflow data into measured power curves. This paper is motivated by an earlier study done at the identical wind farm by Bulaevskaya et al. (2015). In that study the authors used lidar measurements as input into statistical power curve models to estimate power generation uncertainty. Measurements made during the single lidar campaign suggested the presence of significantly large velocity accelerations or hill "speed-ups" encountered by the evaluated turbine, e.g., the nacelle wind speed was often higher than the lidar measurements. With this finding in mind, we designed here a multi-lidar campaign to further study the speed-up behavior of wind flow as it approached the ridgeline turbine. The specific goals of the present study are to (1) characterize the local flow features at the Altamont Pass wind farm, (2) quantify the magnitude of hill "speed-ups" under different atmospheric stability conditions, (3) evaluate the use of vertically-profiling lidar for measuring free-stream inflow in complex terrain, and (4) evaluate the accuracy of measured power curves using the lidar inflow data.

\section{Hill Flow Theory}

As air travels over a complex landscape changes occur to the mean and turbulent components of the flow. These changes may include a decrease or increase in wind shear, wind veer and/or turbulence, and occurrences of negative wind shear (e.g. katabatic flow), lee-side flow separation, and hilltop flow acceleration (e.g., anabatic flow). Here, we concentrate on the latter, as hilltop flow acceleration is the primary reason for the siting of turbines on ridgelines. The acceleration of flow over a hill or ridge crest (i.e., hill "speed-up") is due to a pressure minimum that develops at the top of the hill and is accompanied by streamline convergence on the windward side (e.g., Taylor et al. 1987, Kaimal and Finnigan 1994). A hill speed-up ( $\Delta$ s) 
expression can be used to describe the fraction of change in the wind speed above a hill or ridge to the approaching undisturbed wind speed. Following Eq 1, $\Delta \mathrm{s}$ is a function of the difference between the mean velocity on the top of the hill and the upwind mean velocity (Coppin et al. 1994):

$$
\Delta s(x, z)=\frac{\bar{U}(x, z)-\overline{U_{o}}(z)}{\overline{U_{o}}(z)}
$$

Where, $\bar{U}(\mathrm{x}, \mathrm{z})$ is the mean wind speed at the top of the hill and $\bar{U}_{o}(\mathrm{z})$ is the upwind mean wind speed.

The hill speed-up phenomenon has been studied extensively, in part, using linearized theory based on Jackson and Hunt (1975). This early theory for a simple two-dimensional hill has been expanded and tested to include three-dimensional hills (Hunt et al. 1988a), rougher surfaces (e.g., Finnigan et al. 1990, Cao and Tamura 2006), steeper slopes (e.g., Arya et al. 1987, Weng et al. 2000), escarpments (e.g., Lemelin et al. 1988, Imamura et al. 2003), elongated ridges (e.g., Sacré 1979, Coppin et al. 1994) and effects of thermal stability (e.g., Hunt et al. 1988b, Coppin et al. 1994, Takahashi et al. 2005, Bleeg et al. 2015). Following Hunt et al. (1998a), flow over a simple hill is characterized into three flow regions: an inner layer, middle layer, and outer layer. The inner layer is defined as the region where the flow field is in equilibrium with the surface and flow acceleration, pressure gradient, and divergence of the turbulent momentum flux are all important. In the middle layer the flow is inviscid and rotational and outer layer flow is described as inviscid and irrotational. The outer layer describes the height at which shear in the upwind profile is no longer significant. $\Delta$ s should be highest in the inner region, although during stable 
or strongly stable conditions $\Delta \mathrm{s}$ in the middle and outer layers can also be significantly large (Coppin et al. 1994).

Modern wind turbines generally sit in the fluctuating middle layer although this can change when the atmosphere becomes more stable or more convective. In this study we did not have the necessary measurements to calculate specific layer depths under different stability regimes; instead the calculations for near-neutral conditions are presented here. In near-neutral flow, the inner-layer depth $(l)(\mathrm{m})$, following Hunt et al. (1988a), is calculated from Eq (2):

$$
\frac{l\left(\ln \left(\frac{l}{z_{o}}\right)\right)}{L_{h}}=2 k^{2}
$$

Where, $z_{o}$ is the roughness length $(\mathrm{m}), L_{h}$ is the hill-half length $(\mathrm{m})$, and $k$ is the von Karman constant (0.4). The values for $z_{o}$ and $L_{h}$ are listed in Table 1 . The middle layer height $\left(h_{m}\right)(\mathrm{m})$ for near-neutral flow is calculated from Eq (3):

$$
h_{m}=L_{h}\left[\ln \left(\frac{L_{h}}{z_{o}}\right)\right]^{-1 / 2}
$$

These expressions are based on a simple, isolated hill in near-neutral conditions. In contrast, wind farms in non-flat terrain are almost always placed in locations with far more complex topography (e.g., non-isolated ridgelines, forested hills, etc.) and full range of stability conditions. Even so, it is beneficial to evaluate how the linearized theory of Jackson and Hunt (1975) and Hunt et al. (1988a) compares to real field cases as linearized flow models commonly 
used in the wind industry, e.g., WAsP (Mann et al. 2002), rely on these assumptions (Bleeg et al. 2015).

\section{Site Description and Wind Climatology}

The wind farm studied here is located in the Altamont Pass Wind Region in Northern California, approximately $70 \mathrm{~km}$ east of San Francisco. The exact location and name of the wind farm is proprietary information; for our purposes here, the farm is referred to as the Altamont Pass Wind Farm. The farm consists of 38, EC Class IIA horizontal-axis turbines which are located along the top of roughly parallel ridgelines. The wind turbines are blade-pitch controlled, $1 \mathrm{MW}$ Mitsubishi (MWT62-1000A). Cut-in speed is $3.0 \mathrm{~m} / \mathrm{s}$, rated speed is $12.5 \mathrm{~m} / \mathrm{s}$, and cut-out speed is $25.0 \mathrm{~m} / \mathrm{s}$. Hub-height is $55 \mathrm{~m}$, rotor diameter is $61.4 \mathrm{~m}$ and blade length is $29.5 \mathrm{~m}$. This puts the minimum blade distance above ground at $24 \mathrm{~m}$ and maximum blade distance above ground at $86 \mathrm{~m}$.

The terrain upwind of the Altamont Pass Wind Farm is moderately complex and includes the Cañada de los Vaqueros hills in the Diablo Range (Figure 1). Locally, the hills and ridgelines have maximum heights of around $400 \mathrm{~m}$ although most are $200 \mathrm{~m}$ or less. The area is covered with short, uniform grassland of low canopy roughness. 


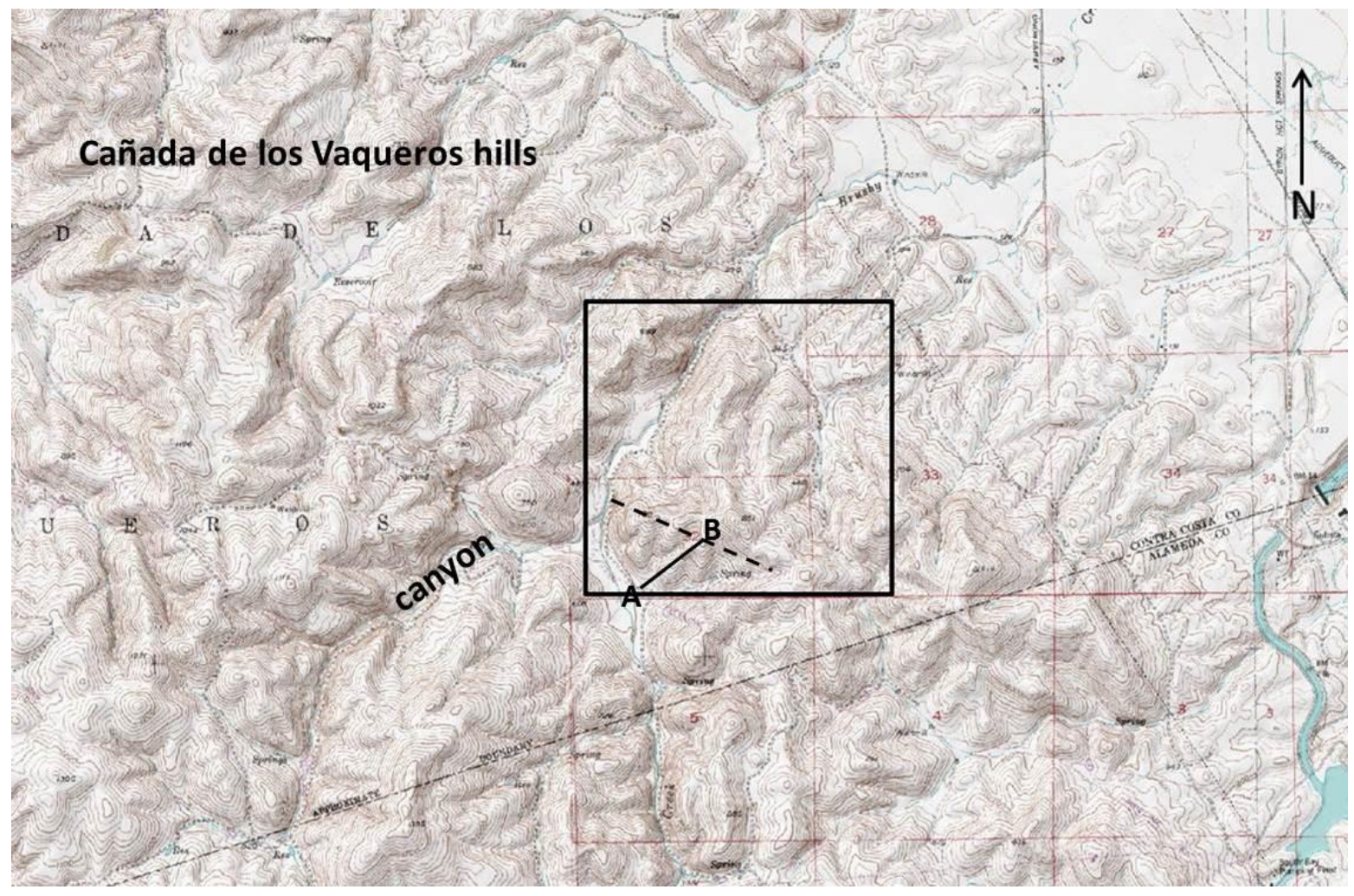

Figure 1: Topographic map of the landscape surrounding the Altamont Pass Wind Farm in Northern California. The approximate location of the farm is bounded by the black box. A shallow canyon runs southwest-northeast and terminates near the wind farm. The studied ridge (dashed line) is perpendicular to the predominant wind direction $\left(230-250^{\circ}\right)$. The terrain profile for line $\mathrm{AB}$ is shown in Figure 3.

Wind speeds peak in the spring and summer in the Altamont Pass Wind Region. During this time flow at the farm is influenced by three topographical features of decreasing scale: the California Coast Range, including the Diablo Range, which influences the regional upper air flow, a $9 \mathrm{~km}$ long canyon just to the west which alters the landscape flow, and the surrounding hills, ridges and small drainage valleys which change the local flow. Summertime regional flow is controlled by a strong diurnal temperature contrast between the interior land and Pacific Ocean which synoptically induces a westerly flow of strong, cooler marine air. The onshore sea breeze is enhanced as winds are channeled through a gap in the Diablo Range towards the interior, lower 
pressure lee side. These winds are influenced by a $9 \mathrm{~km}$ long, $\sim 70 \mathrm{~m}$ deep canyon which enhances and channels the surface layer southwesterly flow. Local ridges at the farm run northwest to southeast and are perpendicular to the predominant southwesterly wind direction. These hills, ridges, and small valleys create unique, localized wind flow patterns near the surface including periods of high wind direction variability (e.g., flow redirected around hills, strong wind veer), negative wind shear (e.g., nocturnal drainage flows), and accelerated flows on the hill and ridgeline crests (i.e., hill speed-up).

\section{Materials and Methods}

\subsection{Continuous wave lidar technology}

This study utilized a commercially available ZephIR 300 vertically-profiling lidar (ZephIR Ltd., North Ledbury, UK). ZephIR 300 is a coherent continuous-wave lidar which operates in the near-infrared band $(\sim 1560 \mathrm{~nm})$. The transmitted laser is focused at each user-defined height to determine the Doppler shift in the backscattered radiation. It uses a conical or velocity-azimuth display (VAD) scan pattern (1 scan per second, 50 measurements per scan, cone half-angle = $30^{\circ}$ ) to compute wind speed and direction. The VAD scan pattern intercepts the wind at various angles building a series of measurements taken around a volume disk of air from which the wind speed is derived. This method assumes that the motion of the aerosols follows that of the wind flow and that the flow across the sample volume is homogenous (Slinger and Harris 2012). Corrections for heterogeneous flow caused by complex terrain are done if needed. These are discussed in Section 4.2. 
Measurement levels are limited to ten heights between $10 \mathrm{~m}$ and $300 \mathrm{~m}$ a.g.l. Each height is not measured simultaneously and instead is measured in series taking $\sim 15$ seconds to resample any given height. Probe depth $(\Delta \mathrm{z})$ is not constant and increases with increasing height. $\Delta \mathrm{z}$ ranges from $1.4 \mathrm{~m}$ at $10 \mathrm{~m}$ a.g.1. to $15.4 \mathrm{~m}$ at $100 \mathrm{~m}$. Reported measurements include the high frequency collection of horizontal wind speed $(\mathrm{U}, \mathrm{m} / \mathrm{s})$, wind direction $\left({ }^{\circ}\right)$, and vertical wind speed $(\mathrm{w}, \mathrm{m} / \mathrm{s})$ calculated from the VAD technique for each measurement height, and 10-minute mean values of horizontal wind speed $(\bar{U}, \mathrm{~m} / \mathrm{s})$, vertical wind speed $(\bar{w}, \mathrm{~m} / \mathrm{s})$, wind direction $\left(^{\circ}\right)$, and horizontal turbulence intensity (TI, \%). 10-minute turbulence kinetic energy (TKE, $\mathrm{m}^{2} / \mathrm{s}^{2}$ ) was calculated using the high frequency variance measurements during post-processing. TKE is used here as the primary turbulence metric as TKE includes all measurable sources of turbulence, both convective and mechanically generated, while horizontal TI does not. For a full discussion on the differences between TI and TKE in wind energy applications see Wharton and Lundquist (2012a). Reported accuracy for the ZephIR in ideal site conditions (e.g., flat, homogenous surface) is $\pm 0.25 \%$ for wind speed and $\pm 0.25^{\circ}$ for wind direction.

\subsection{CFD corrections for complex terrain}

Lidar technology is distinct from a cup or sonic anemometer in that the instrument samples the wind across a relatively large volume of air. In complex terrain, assumptions about the horizontal homogeneity of the flow across the volume space may be invalid. Because this assumption is used in the calculation of wind speed, a lidar's accuracy in complex terrain is reduced. The wind speed measurements presented here were corrected for terrain-induced heterogeneous flow errors during post-processing using the Dynamics software (ZephIR Ltd.). Dynamics, based on the 
work of Bingöl et al. (2009), converts raw lidar line-of-sight velocity data into precise, unbiased measurements of wind speed and wind direction for hilly sites (Pitter et al. 2012). Input into Dynamics includes the airflow simulations made with VENTOS, a Computational Fluid Dynamics (CFD) model, for the exact latitude and longitude coordinates of each lidar. This correction technique has been validated against cup anemometry at eight sites in complex terrain with high accuracy (Pitter et al. 2012). These correction factors were up to $11 \%$ for the most complex location although generally less than $2 \%$ for all other sites.

For our wind farm, the Dynamics conversion factors for all wind directions and measurement heights ranged from $+1 \%$ to $+8 \%$ for the hill lidar, indicating the presence of dominant upslope flows, and $-4 \%$ to $+1 \%$ at the base lidar, indicating the presence of downslopes induced by the upwind terrain. Although these ranges are relatively large, the correction factors associated with the predominant wind direction were closer to zero: $+3 \%$ for the hill lidar and $-2 \%$ for the base lidar.

\subsection{Inter-comparison of lidars}

Prior to the field campaign at the Altamont Pass Wind Farm, the two ZephIR 300 units were placed side by side in a flat, open grass field at the Lawrence Livermore National Laboratory in Livermore, California (37.6905, -121.7163, $174 \mathrm{~m}$ a.s.1.) to evaluate instrument agreement. The inter-comparison lasted from 31 May - 4 June 2013. The units were placed $20 \mathrm{~m}$ apart on very flat land with no trees, buildings or other obstructions within $150 \mathrm{~m}$. Both lidars were set up in an identical manner and used solar and battery power. Measurements were taken every $10 \mathrm{~m}$ from 10-100 m above ground level for a total of ten heights. Steps were made to ensure that both 
instruments were aligned with true north, however an offset of $2.5^{\circ}$ was later found in the data indicating a slight misalignment during deployment. This offset was removed from the datasets during post-processing. During the inter-comparison period mean vertical wind speeds for each instrument were $-0.012 \mathrm{~m} / \mathrm{s}$ and $-0.010 \mathrm{~m} / \mathrm{s}$.

Box plot histograms of instrument measurement differences for wind speed and direction are plotted as a function of height in Figure 2. Wind speed comparisons between the units showed excellent agreement at all heights, especially above $40 \mathrm{~m}$. No noticeable biases were found for either instrument. $25^{\text {th }}$ and $75^{\text {th }}$ percentiles for instrument differences were within $\pm 0.1 \mathrm{~m} / \mathrm{s}$ for all heights. Linear correlation (Pearson's r) values ranged from 0.990 at $10 \mathrm{~m}$ to 0.997 at $100 \mathrm{~m}$; slopes ranged from 0.983 to 1.005 (not shown). Agreement in wind direction was also excellent and the $25^{\text {th }}$ and $75^{\text {th }}$ percentiles for instrument differences were within $\pm 3^{\circ}$. Pearson's $r$ values ranged from 0.981 for $10 \mathrm{~m}$ to 0.99 for $100 \mathrm{~m}$; slope ranged from 0.984 to 1.005 (not shown). 


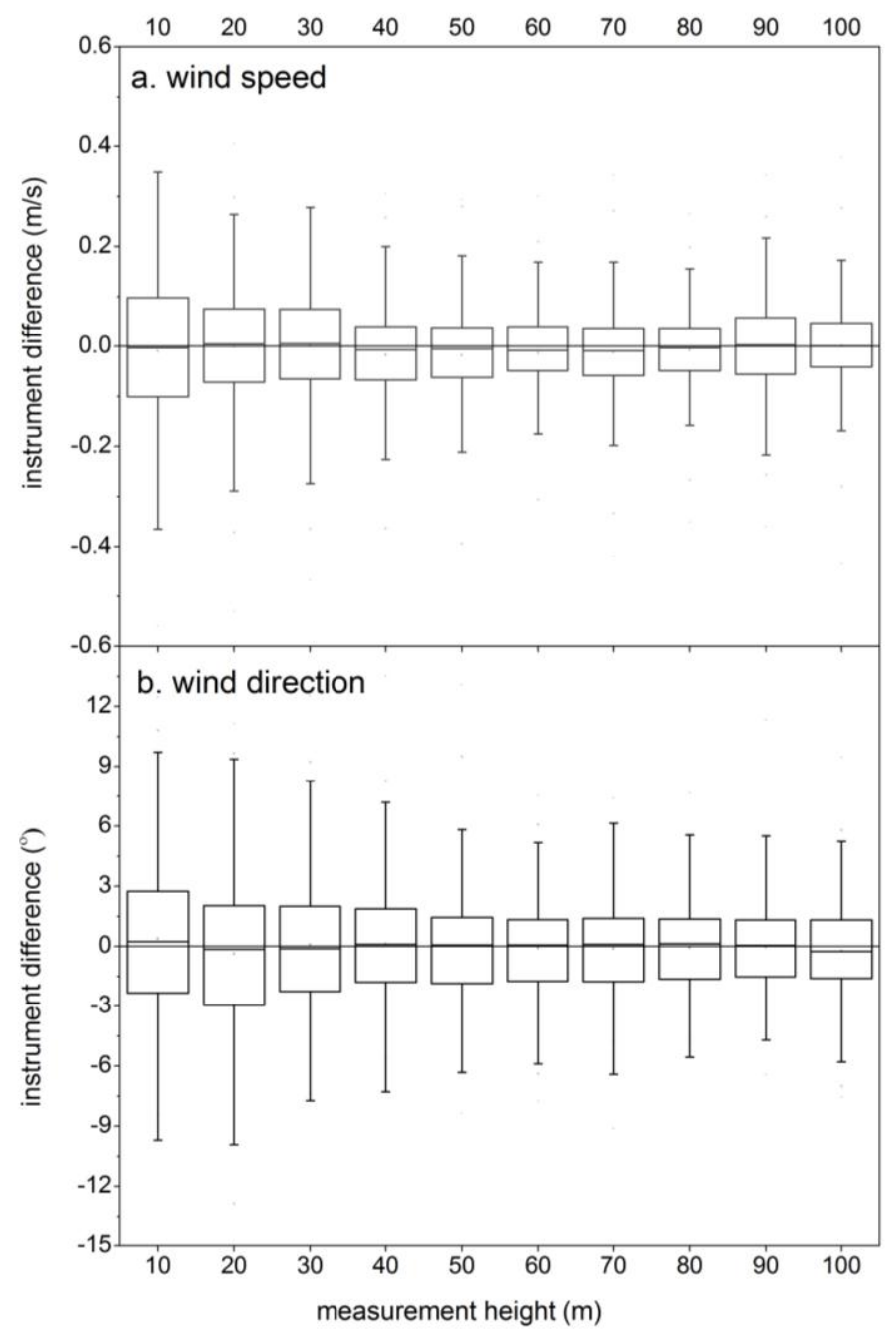

Figure 2: Box plot histograms of 10-minute wind speed and wind direction differences between the two lidars show excellent agreement and no noticeable instrument biases during the intercomparison period at LLNL. Instrument agreement is slightly higher for measurement levels above $40 \mathrm{~m}$. The plots show the mean (dot), median (horizontal line), $25^{\text {th }}$ and $75^{\text {th }}$ percentiles (box), and $5^{\text {th }}$ and $95^{\text {th }}$ percentiles (whiskers). 


\subsection{Wind farm field campaign: experimental setup and available measurements}

The two lidars were deployed at the Altamont Pass Wind Farm from 10 June- 14 August 2013 coinciding with the peak power season. Weather conditions during the deployment included warm to hot daytime temperatures, cool to mild nights, a strong late afternoon sea breeze, clear afternoon skies and no precipitation. The lidars were deployed to measure wind flow at the base (called the "base lidar") and three-fourths of the ways up the windward slope (called the "hill lidar") of a $140 \mathrm{~m}$ tall, elongated ridge. This setup captured the air flow as it approached and moved up and along the ridge towards an unwaked turbine, T08 (Figure 3). Both units were powered with identical solar and battery units. Additional experimental details and ridge characteristics are listed in Table 1. 


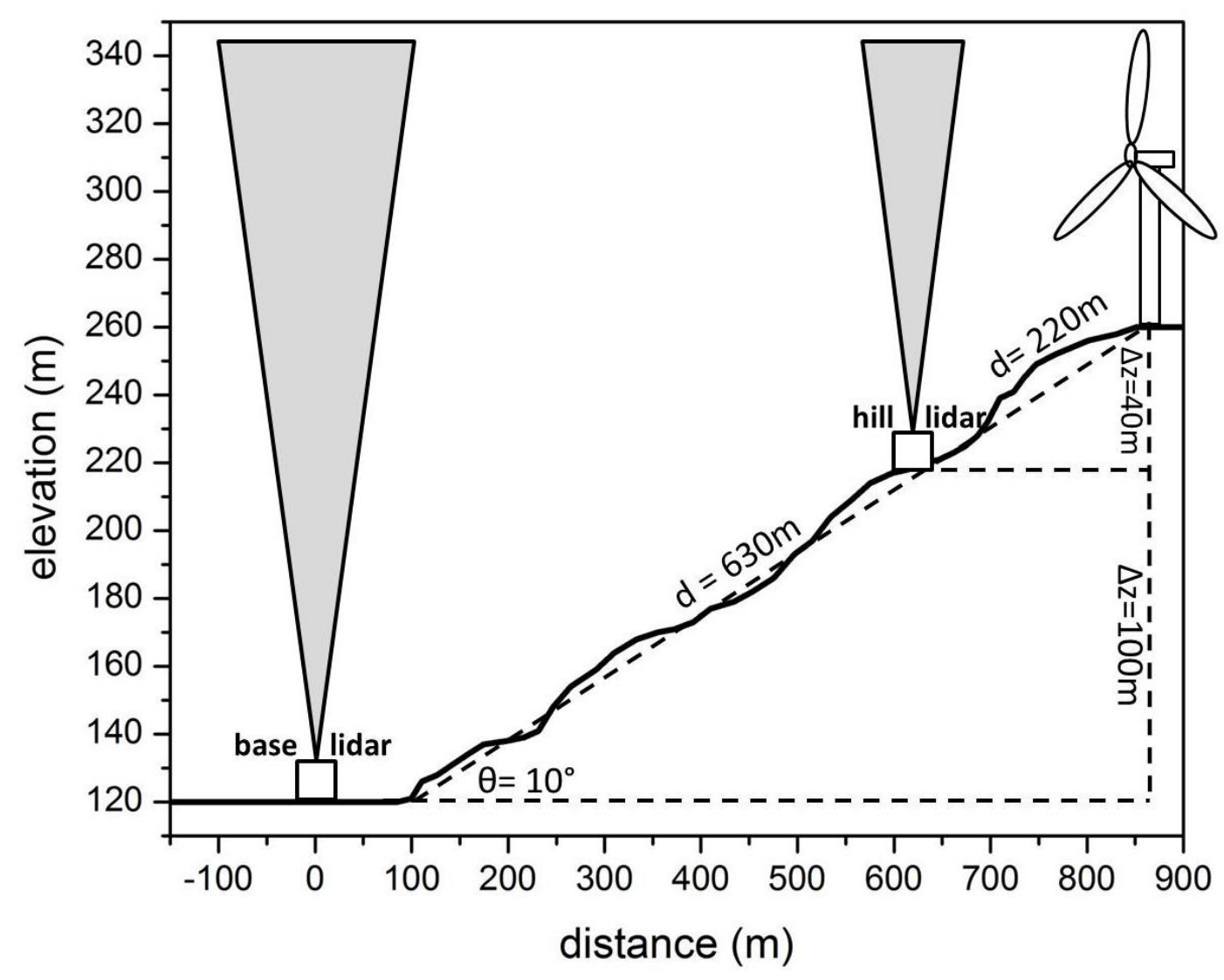

Figure 3: Terrain profile for the line $\mathrm{AB}$ in Figure 1 and schematic of the experimental design. Shown are the locations of the base lidar, hill lidar, and turbine T08. $d=$ ground distance.

Table 1: Characteristics of the studied ridge and experimental details. $D$ is rotor diameter distance. $\mathrm{z}_{\mathrm{o}} \sim 0.10 *$ canopy height.

\begin{tabular}{|l|l||l|l|}
\hline \multicolumn{2}{|c||}{ Ridge characteristics } & \multicolumn{2}{c|}{ Experimental details } \\
\hline Length of elongated ridge & $\sim 3 \mathrm{~km}$ & Base lidar elevation & $120 \mathrm{~m}$ a.s.l. \\
\hline Ridge height $(h)$ & $140 \mathrm{~m}$ & Hill lidar elevation & $220 \mathrm{~m}$ a.s.l. \\
\hline Ridge length $(L)$ & $740 \mathrm{~m}$ & T08 elevation & $260 \mathrm{~m}$ a.s.l. \\
\hline Ridge half length $\left(L_{h}\right)$ & $362 \mathrm{~m}$ & Base lidar distance to T08 & $630 \mathrm{~m}$ or $10.3 \mathrm{D}$ \\
\hline Mean ridge slope & $10^{\circ}$ & Hill lidar distance to T08 & $220 \mathrm{~m}$ or $3.6 \mathrm{D}$ \\
\hline Surface roughness $\left(z_{0}\right)$ & $\sim 0.02 \mathrm{~m}$ & Bearing of lidars from T08 & $238^{\circ}$ \\
\hline
\end{tabular}


Nacelle cup anemometer (NRG \#40, NRG Systems, Hinesburg, Vermont, USA) measurements on turbine T08 provided 10-minute, mean hub-height wind speed measurements at the top of the ridge. A lidar was not placed at the top of the ridge because the distance between neighboring turbines was too near for a clean, blade-free measurement which would have otherwise required a shutdown of T08 and the adjacent turbines. Exact measurement heights for each lidar are listed in Table 2. In brief, the lidars were configured to optimize overlapping measurements so that a large number of equivalent heights above ground level were measured by both lidars. The lidars were also programmed to measure heights equivalent to the nacelle hub-height (55 m a.g.l.), and minimum (24 m a.g.l.) and maximum (86 m a.g.l.) blade tips of T08.

Table 2: Measurement height details for the lidars and turbine T08. Overlapping lidar measurement levels include eight heights above ground level and five heights above sea level. Bolded numbers are those taken at heights equivalent to nacelle hub-height. The turbine only has one wind speed measurement available which is at hub-height or $55 \mathrm{~m}$ a.g.l.

\begin{tabular}{|l||l|l|l||l|l|l||}
\hline $\begin{array}{l}\text { Measurement } \\
\text { level }\end{array}$ & $\begin{array}{l}\text { Base lidar } \\
(\mathrm{m}) \text { (a.g.l.) }\end{array}$ & $\begin{array}{l}\text { Hill lidar } \\
(\mathrm{m}) \text { (a.g.1.) }\end{array}$ & $\begin{array}{l}\text { Turbine T08 } \\
(\mathrm{m}) \text { (a.g.l.) }\end{array}$ & $\begin{array}{l}\text { Base lidar } \\
(\mathrm{m}) \text { (a.s.1.) }\end{array}$ & $\begin{array}{l}\text { Hill lidar } \\
(\mathrm{m}) \text { (a.s.l.) }\end{array}$ & $\begin{array}{l}\text { Turbine T08 } \\
(\mathrm{m}) \text { (a.s.l.) }\end{array}$ \\
\hline Ground level & 0 & 0 & 0 & 120 & 220 & 260 \\
\hline 1 & 10 & 10 & $\mathbf{5 5}$ & 130 & 230 & $\mathbf{3 1 5}$ \\
\hline 2 & 24 & 24 & & 144 & 244 & \\
\hline 3 & 38 & 38 & & 158 & 258 & \\
\hline 4 & $\mathbf{5 5}$ & $\mathbf{5 5}$ & & $\mathbf{1 7 5}$ & $\mathbf{2 7 5}$ & \\
\hline 5 & 75 & 63 & & 195 & 283 & \\
\hline 6 & 86 & 75 & & 206 & 295 & \\
\hline 7 & 112 & 86 & & 232 & 306 & \\
\hline 8 & 124 & 94 & & 244 & 314 & \\
\hline 9 & 163 & 112 & & 283 & 332 & \\
\hline 10 & 194 & 120 & & 314 & 340 & \\
\hline 11 & 225 & 125 & & 345 & 345 & \\
\hline
\end{tabular}


Measurements were not available to calculate an on-site stability parameter such as the Obukhov length, which would require a 3-D sonic anemometer, or the Richardson number $\left(R_{i}\right)$, which would require a wind speed and air temperature profile. Instead, we estimated atmospheric stability by looking at profile measurements from a $52 \mathrm{~m}$ tall meteorological tower at LLNL (37.6905, $-121.7163,174 \mathrm{~m}$ a.s.l.) located about $12 \mathrm{~km}$ from the wind farm. From these data a bulk Richardson number $\left(R i_{b}\right)$ was approximated using Eq (4) (Stull 1988):

$$
R i_{b}=\frac{g}{\theta_{v}} \frac{\left(\theta_{v 2}-\theta_{v 1}\right)\left(z_{2}-z_{1}\right)}{\left(U_{2}-U_{1}\right)^{2}}
$$

where $g$ is gravitational acceleration $\left(\mathrm{m} / \mathrm{s}^{2}\right), \theta_{v}$ is mean virtual potential temperature $(\mathrm{K}), z$ is measurement height $(\mathrm{m}), U$ is mean horizontal wind speed $(\mathrm{m} / \mathrm{s})$, and the subscripts 1 and 2 are respectively, the lower $(10 \mathrm{~m})$ and upper measurement level $(52 \mathrm{~m})$. Time periods were defined as stable, convective, or near-neutral depending on whether $R i_{b}$ was positive, negative, or nearzero, respectively. The stability classes, as expected, followed the time of day closely with the hours (in Pacific Standard Time, PST) of 21:00-6:00 classified on average as stable, 7:00-9:00 and 18:00-21:00 as near-neutral, and 9:00-17:00 as convective. Here $R_{i b}$ was used as a proxy for determining stable, convective and near-neutral conditions; however, the exact magnitudes of $R_{i b}$ were not used in further analyses as these values were taken off-site and may not represent actual values at the wind farm.

A shear exponent $(\alpha)$ was calculated from the 10-minute lidar wind speed measurements taken at heights of $124 \mathrm{~m}\left(\mathrm{z}_{2}\right)$ and $10 \mathrm{~m}\left(\mathrm{z}_{1}\right)$ a.g.l (Eq 5). Alpha provides a means for quantitatively comparing the wind speed profiles from both lidar locations. 


$$
U\left(z_{2}\right)=U\left(z_{1}\right)\left(\frac{z_{2}}{z_{1}}\right)^{\alpha}
$$

A larger shear exponent indicates a more stable atmosphere with possible decoupling between the land surface and air aloft while a lower shear exponent indicates a well-mixed, convective atmosphere. Details regarding the significance of shear on wind power generation are found in Wagner et al. (2009) and Wharton and Lundquist (2012b). In brief, large shear can alter power generation through changing the average rotor-disk wind speed and by increasing the amount of out-of-plane loads on the turbine blades. While the first may lead to an increase in power production, high loads on turbine components can cause reduced power generation and if very high, can damage turbine components.

Turbine power production is routinely plotted as a function of hub-height wind speed (called a measured power curve) obtained either from a cup anemometer mounted on a turbine nacelle or, if available, from an upwind, free-stream instrument (here we used the hill lidar). To test the sensitivity of the power curve response to different sources of input, we evaluated T08 power output as a function of four wind speeds. These included:

1. The turbine nacelle wind speed taken at hub-height

2. The lidar wind speed taken at hub-height

3. The hub-height lidar wind speed adjusted for a stability-dependent hill-speed up effect 4. The equivalent rotor-disk lidar wind speed adjusted for a stability-dependent hill speed-up effect 
Although the first two listed wind speeds are actual measurements taken at hub-height they have limited use for interpreting turbine power response. First, the nacelle wind speed may not reflect true inflow conditions at the top of the ridge because the instrument is located behind rotating blades when the turbine is operating. This creates flow distortion usually in the form of reduced velocity and increased turbulence intensity as compared to the free-stream inflow. Second, the lidar may not reflect the true inflow into turbine T08 due to topography-induced changes on the flow between the two locations.

With these limitations in mind, we adjusted the lidar measurements for site topography and calculated a third and fourth wind speed. An adjustment factor was calculated by multiplying the lidar wind speed $\left(U_{\text {lidar }}, \mathrm{m} / \mathrm{s}\right)$ by the average stability-dependent hill speed-up factor $(\Delta \mathrm{s})$. The adjustment factor was then added to $U_{\text {lidar }}$ to produce an estimate of the free-stream, hub-height wind speed $\left(U_{\text {adjusted }}, \mathrm{m} / \mathrm{s}\right)$ found at the top of the ridge. Alternatively, we used the average stability-dependent hill speed-up factor ( $\Delta \mathrm{s})$ to adjust the equivalent rotor-disk wind speed ( $\left.U_{\text {equiv }}, \mathrm{m} / \mathrm{s}\right) . U_{\text {equiv }}$ includes wind speed information at multiple heights taken by the lidar to estimate average inflow seen by the entire rotor disk of the turbine. Here, we used five measurement heights equivalent to those found in the rotor-disk. For more details on how $U_{\text {equiv }}$ is calculated see Wagner et al. (2009).

\subsection{Data filtering}

The field campaign collected measurements from over 7,000 10-minute data periods. During post-processing the measurements were filtered using the following methodology: 
1. Screened for quality control - turbine power data were removed if the turbine was not functioning properly according to the SCADA quality control flags. The lidar measurements were QC-ed by internal algorithms during data collection which maximize the signal-to-noise ratio and remove the effects of clouds (Slinger and Harris 2012). (6534 data points remained)

2. Simultaneously measured data - lidar (all measurement heights) and turbine (nacelle wind speed, power output) measurements were filtered to remove any time periods that did not include simultaneously measured data. (4545 data points remained)

3. Screened for wind direction - lidar measurements used in all wind speed profiles were filtered to only include wind directions between $230^{\circ}-250^{\circ}$. This wind sector put the lidars directly upwind of turbine T08. The turbine wind data were not also screened because the nacelle-mounted wind vane measurements were not accurate. All measurements were filtered once more to remove any data points that did not have simultaneously measured data. (1902 data points remained)

4. Segregated by stability class - the remaining data were lastly filtered into stable, nearneutral or convective stability classes using the Bulk Richardson number (see Eq 4).

\section{Results}

\subsection{Ridge atmospheric layer depth}


The height of the turbines at the Altamont Pass Wind Farm makes them subject to residing in fluctuating atmospheric layers. Following Eq (2), the inner atmospheric layer $(l)$ on the top of the ridge was estimated to extend $17 \mathrm{~m}$ above the surface in near-neutral conditions. This places even the lowest height of the blade tip ( $24 \mathrm{~m}$ ) above the lowest surface layer. However, the depth of this layer may increase during a convective stability regime and part of the turbine blades could experience the distinct flow conditions found in the inner layer during well-mixed conditions. The middle layer $\left(h_{m}\right)$ was estimated using Eq (3) to be $115 \mathrm{~m}$ deep in near-neutral conditions. As the blades reach a maximum height of $86 \mathrm{~m}$, the turbines sit within the middle layer at this site during near-neutral conditions. During stable conditions, however, the inner and middle layers are expected to decrease in depth and the turbines may partially reside in the outer layer as well.

\subsection{Topography and wind direction}

At the base lidar the percentage of winds from $230-250^{\circ}$ ranged from $42 \%$ at $10 \mathrm{~m}$ a.g.1. to $53 \%$ at $162 \mathrm{~m}$ a.g.l. At the hill lidar, the percentage of winds from $230-250^{\circ}$ ranged from $44 \%$ at $10 \mathrm{~m}$ a.g.l. to $57 \%$ at $124 \mathrm{~m}$ a.g.l. The wind roses indicated that the orientation of each lidar was slightly offset from true north even though steps were made to ensure that they both faced true north. This disagreement is seen in the small shift between the dominant wind direction at the base lidar $\left(238-242^{\circ}\right)$ and the hill lidar $\left(240-244^{\circ}\right)$ during well-mixed conditions (Figure 4). This offset was independent of wind direction indicating that a heading error occurred during instrument deployment. The misalignment, however, was less than five degrees. Wind direction was most uniform during the midday hours when the atmosphere was wellmixed. For these hours (10:00 - 14:00 PST), wind direction changed little with height and 
changed little between lidar locations (Figure 4). Both lidar locations experienced a narrow wind direction sector around $235-245^{\circ}$. This direction is indicative of channeling of the synoptic-scale sea breeze through a gap in the Coastal Range.

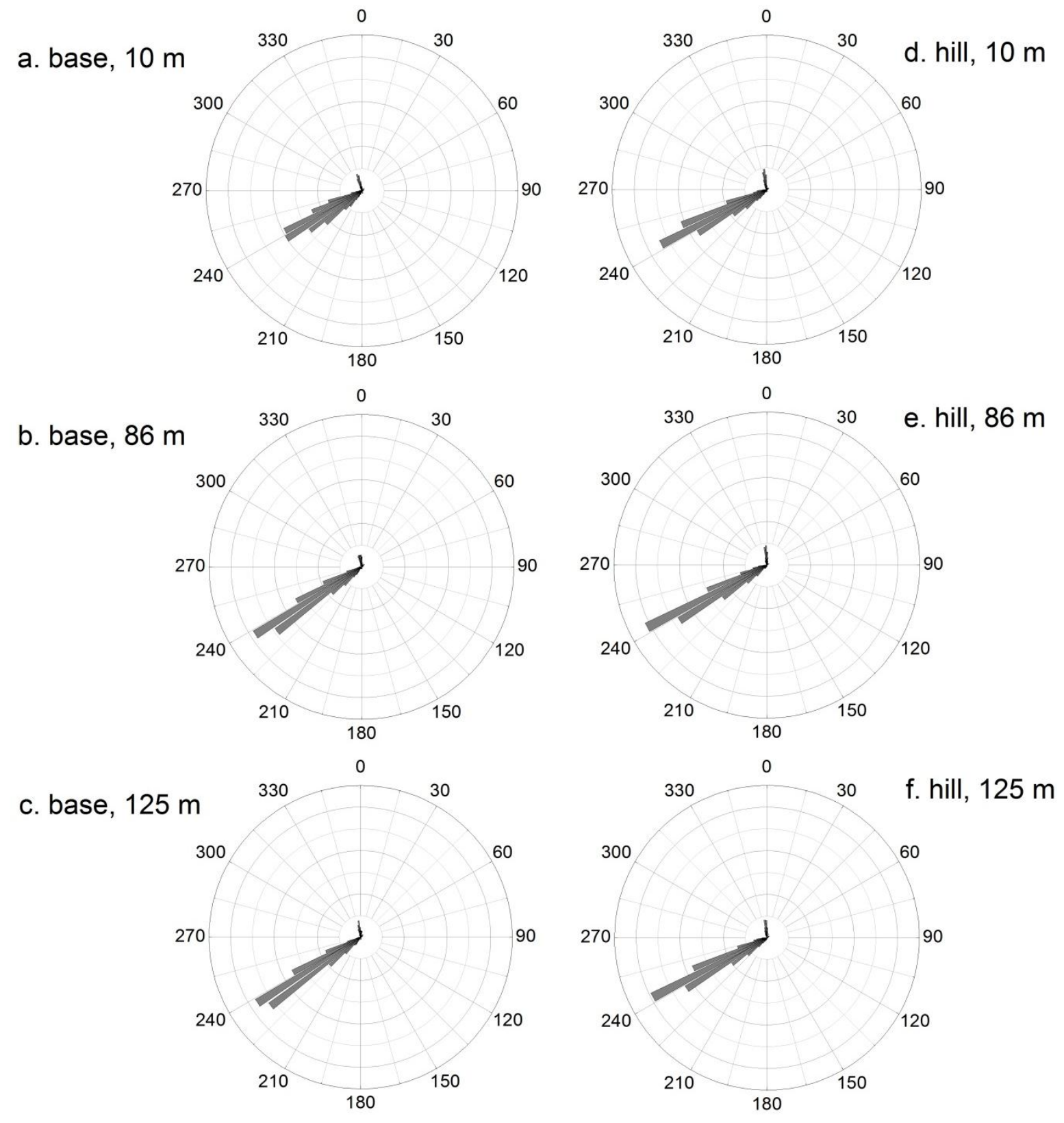

Figure 4: Wind roses as a function of selected measurement heights for both lidars during convective conditions. 
The nighttime (22:00 - 4:00 PST) wind direction plots had greater variability indicating a stronger influence of local terrain during stable conditions. The nighttime wind roses also indicated the presence of a flow obstruction which re-directed the near-surface flow at the base lidar (Figure 5a). Near to the ground $(<60 \mathrm{~m})$, the nocturnal winds at the bottom of the ridge came from either the southwest or south-southeast as it appears that a portion of the southsouthwesterly surface flow is obstructed and re-directed to the south-southeast by a $220 \mathrm{~m}$ tall hill that is orientated $190-205^{\circ}$ from the base lidar (Figure 6b). This near-surface flow obstruction is not evident at the hill lidar (Figure 5d). Between $60 \mathrm{~m}$ and $112 \mathrm{~m}$ a.g.l. the flow at the base lidar is more strongly channeled in a narrow southwesterly direction, most likely from the southwest-northeast orientated, 9-km long, $70 \mathrm{~m}$ deep canyon. Above $122 \mathrm{~m}$ a.g.l. it appears that the local terrain plays less of a role in determining wind direction as the wind roses at both lidars are almost identical. Figures 6-8 show the dominant wind vectors at each lidar plotted on 3-D topographical maps for heights equivalent to the near-surface $(10 \mathrm{~m})$, top of the rotor-disk (86 m), and air aloft (125 m). 


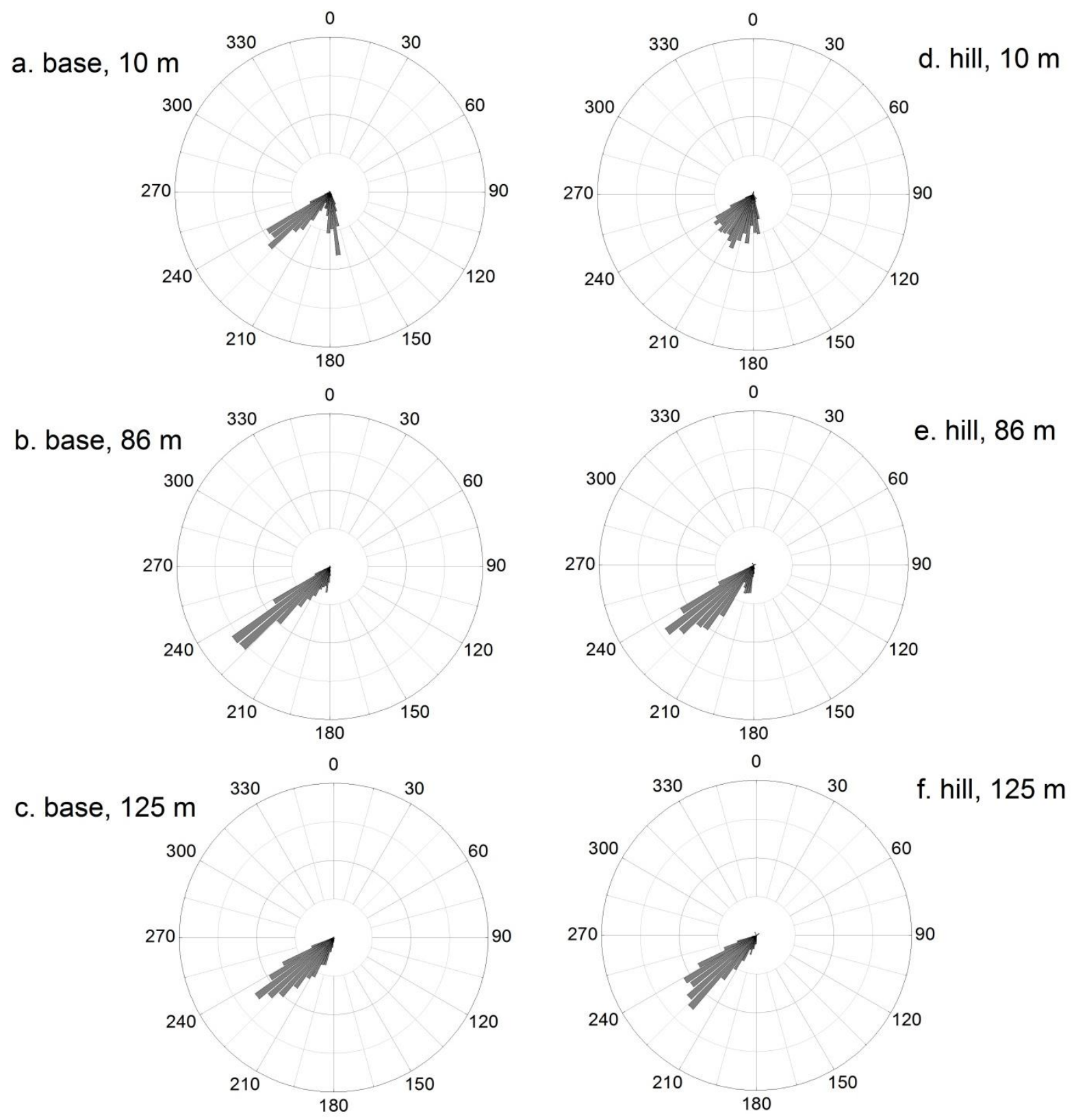

Figure 5: Same as Figure 4, except during stable conditions. 


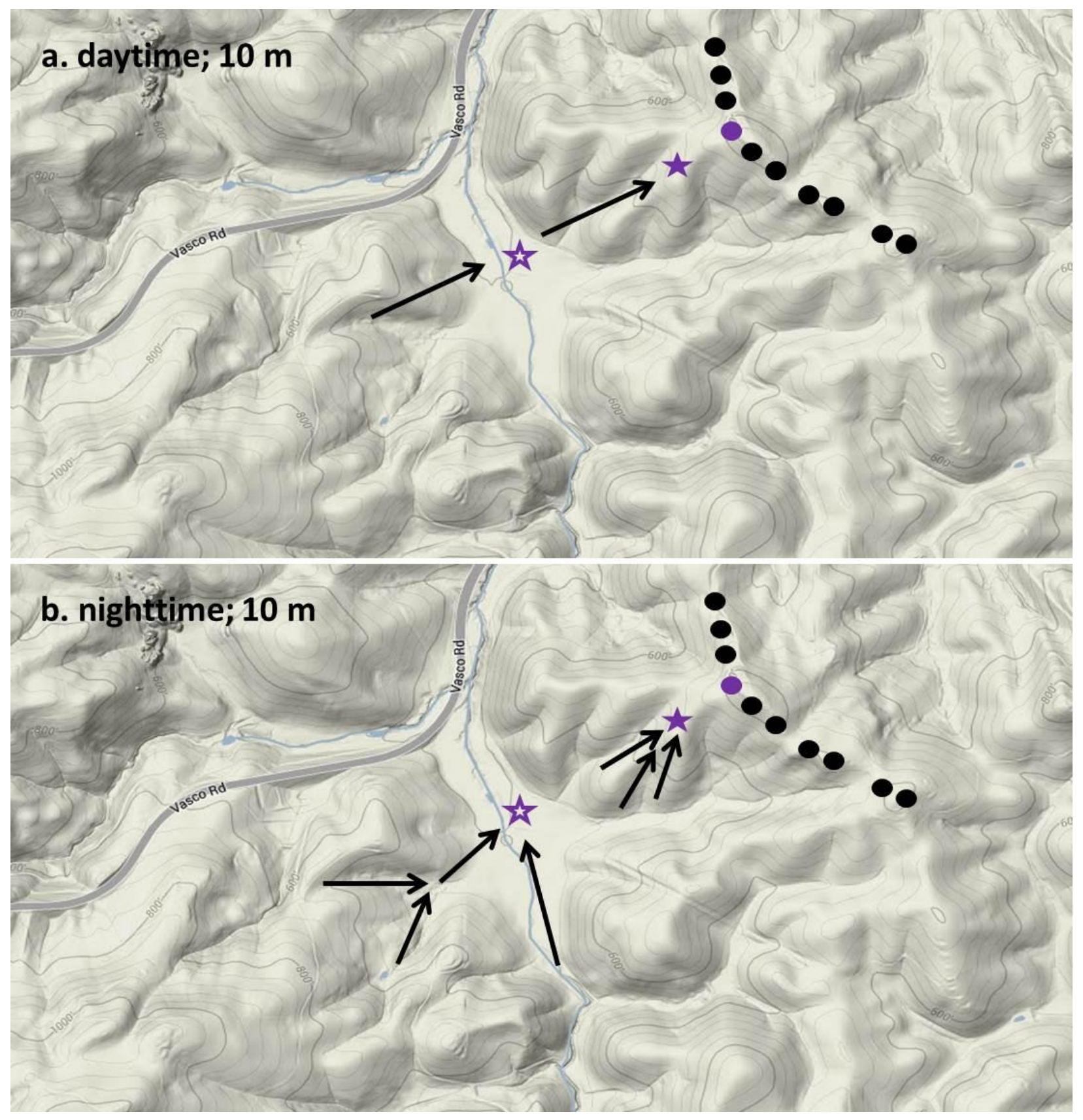

Figure 6: Most frequent (a) daytime and (b) nighttime near-surface (10 m a.g.l.) wind directions at each lidar mapped on a 3-D topographical map. Turbine T08 is highlighted in purple and is located in the row of unwaked turbines (black dots) for the southwest wind direction. The hill lidar is a solid star and the base lidar is represented by an open star symbol. 


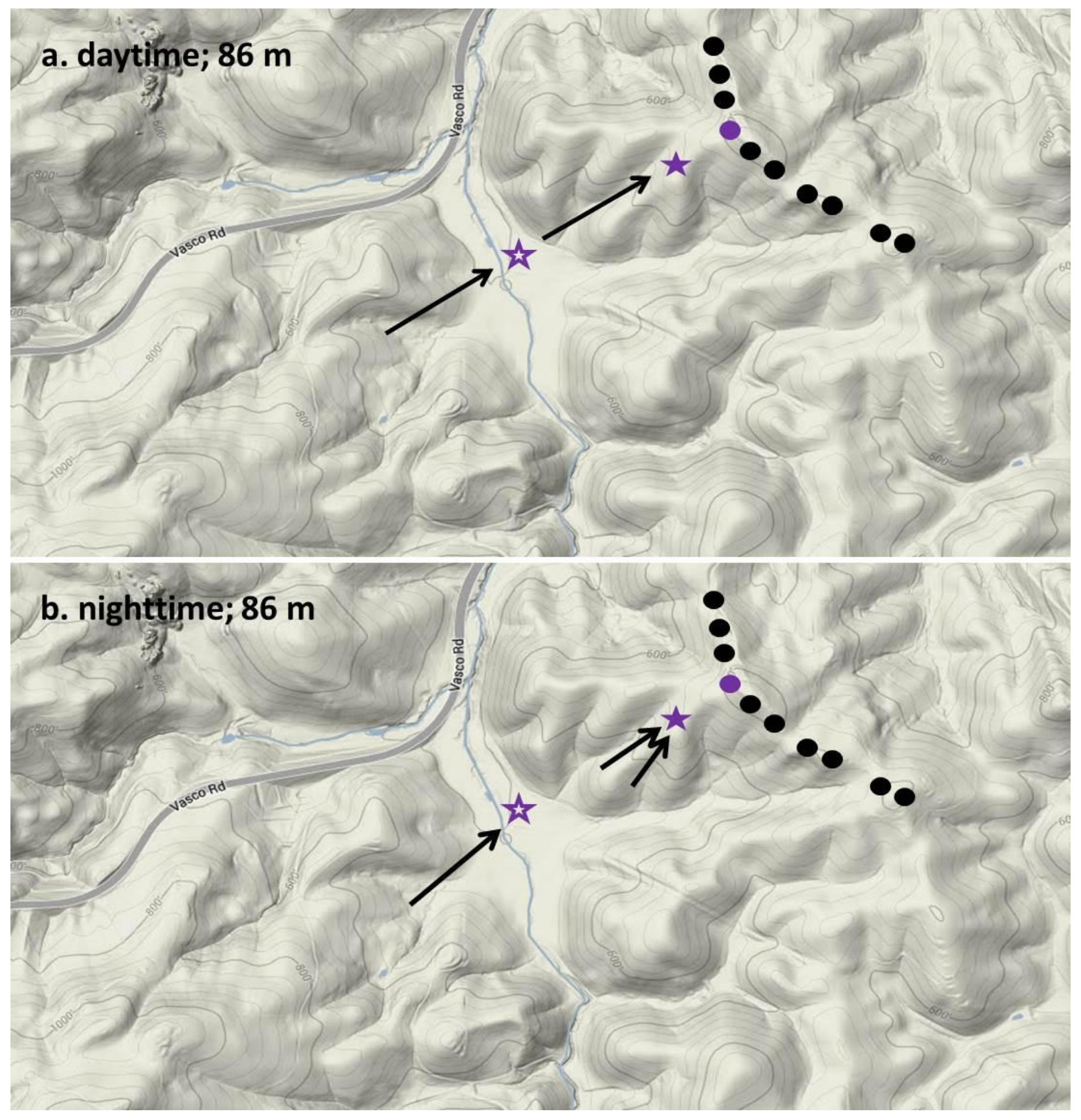

Figure 7: Same as Figure 6, except most frequent wind directions are shown for the $86 \mathrm{~m}$ height. 


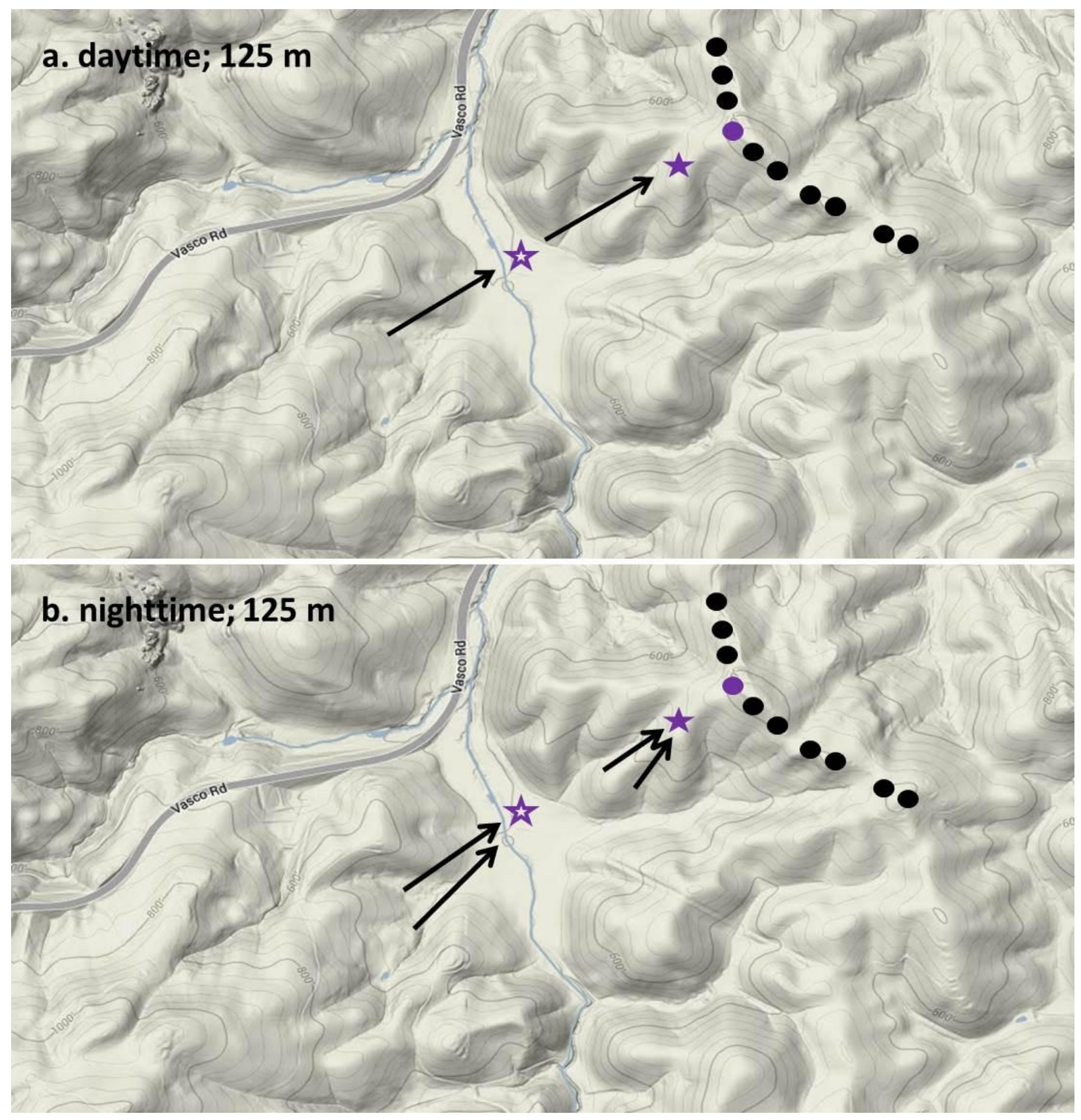

Figure 8: Same as Figure 6, except most frequent wind directions are shown for the $125 \mathrm{~m}$ height.

Directional wind shear, or veer, is plotted in Figure 9 for heights representing the approximate bottom half (24 to $55 \mathrm{~m}$ ) and top half (55 to $86 \mathrm{~m}$ ) of the turbine rotor disk. Overall, median veer 
averaged from $0^{\circ}$ to nearly $6^{\circ}$ at the lidar locations, although veer as high as $40^{\circ}$ was occasionally observed. Upon closer examination, a couple of patterns emerge from the histograms. First, veer tends to be slightly greater nearer to the surface (i.e., at heights equivalent to the bottom half of the rotor disk) than at higher heights. Second, veer differed in magnitude by lidar location. During midday hours, slightly higher amounts of veer were observed at the base lidar $\left(\right.$ median $\left.=0.8^{\circ}\right)$ than the hill lidar $\left(\right.$ median $\left.=0.2^{\circ}\right)$. The hill lidar at night, however, saw significantly higher veer $\left(\right.$ median $\left.=5.5^{\circ}\right)$ than the base location $\left(\right.$ median $\left.=0.6^{\circ}\right)$.

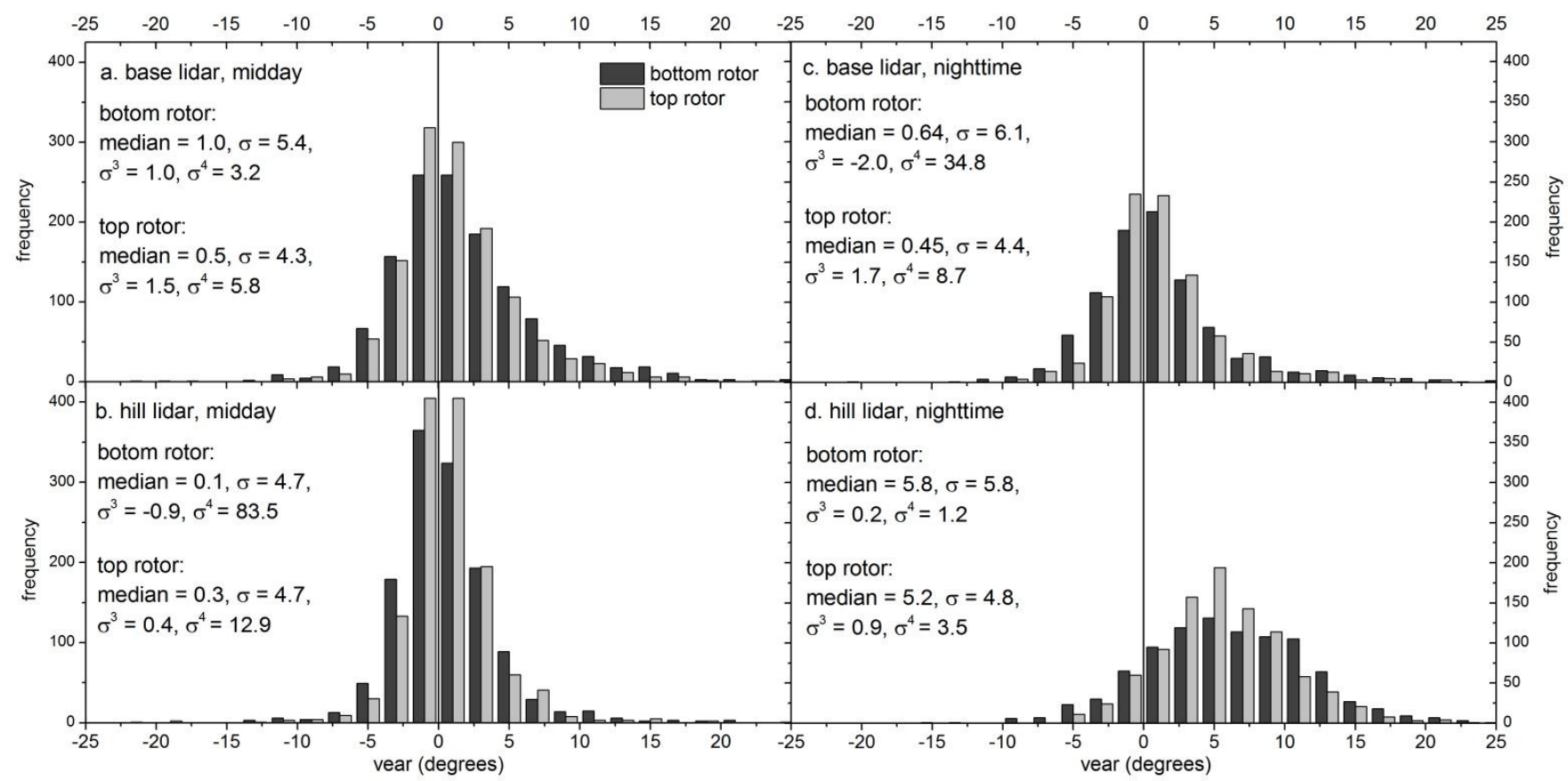

Figure 9: Wind veer statistics (median, standard deviation, skewness, kurtosis) for the base and hill lidars at heights equivalent to the bottom and top half of the rotor disk. Note the high amount of veer at the hill lidar at night.

Mean flow inclination angles by wind sector were calculated using the 10-minute lidar-measured vertical and horizontal wind speeds taken at $55 \mathrm{~m}$ a.g.l. These angles provide an indication of the complexity of terrain surrounding the front row turbines as the near-surface flow follows the 
terrain slope. Mean flow inclination angles (with respect to the horizontal) are listed in Table 3 for each $45^{\circ}$ wind sector for the base and hill lidar locations. Here we observed inflow angles up to 8 degrees near the top of the ridge for the predominant southwesterly wind direction. This flow inclination angle implies that there is a significant non-horizontal component in the southwesterly flow as it approaches turbine T08.

Table 3: Mean flow inclination angle (in degrees) at each lidar by wind direction sector. Mean negative angles represent downslope flows; mean positive angles are upslope flows.

\begin{tabular}{|l|l|l|l|l|l|l|l|l|}
\hline & 0 & 45 & 90 & 135 & 180 & 225 & 270 & 315 \\
\hline Base location & $-1.2^{\circ}$ & $-1.8^{\circ}$ & $-0.6^{\circ}$ & $0.5^{\circ}$ & $3.3^{\circ}$ & $3.1^{\circ}$ & $0.6^{\circ}$ & $0.9^{\circ}$ \\
\hline Hill location & $-3.5^{\circ}$ & $-4.8^{\circ}$ & $-4.5^{\circ}$ & $2.0^{\circ}$ & $4.0^{\circ}$ & $7.6^{\circ}$ & $4.7^{\circ}$ & $1.0^{\circ}$ \\
\hline
\end{tabular}

\subsection{Turbulence kinetic energy}

The calculation of TKE allowed us to compare the profiles of 3-dimensional turbulence between the two lidar locations. An equivalent measure of turbulence at the top of the ridge, however, is not shown as cup anemometry does not allow for the calculation of TKE. Plotted in Figure 10 are the vertical profiles of TKE for the two lidars segregated by stability class. The largest differences in TKE between lidars occurred nearer to the surface $(<40 \mathrm{~m})$ and during stable conditions. During these conditions TKE at the bottom of the hill was larger than found near the top. These differences decreased with height and TKE magnitudes were almost identical at both locations above $55 \mathrm{~m}$ during convective and near-neutral conditions and above $38 \mathrm{~m}$ during stable conditions. This finding further suggests that the depth of the inner layer was shallower during stable conditions than during other times. 


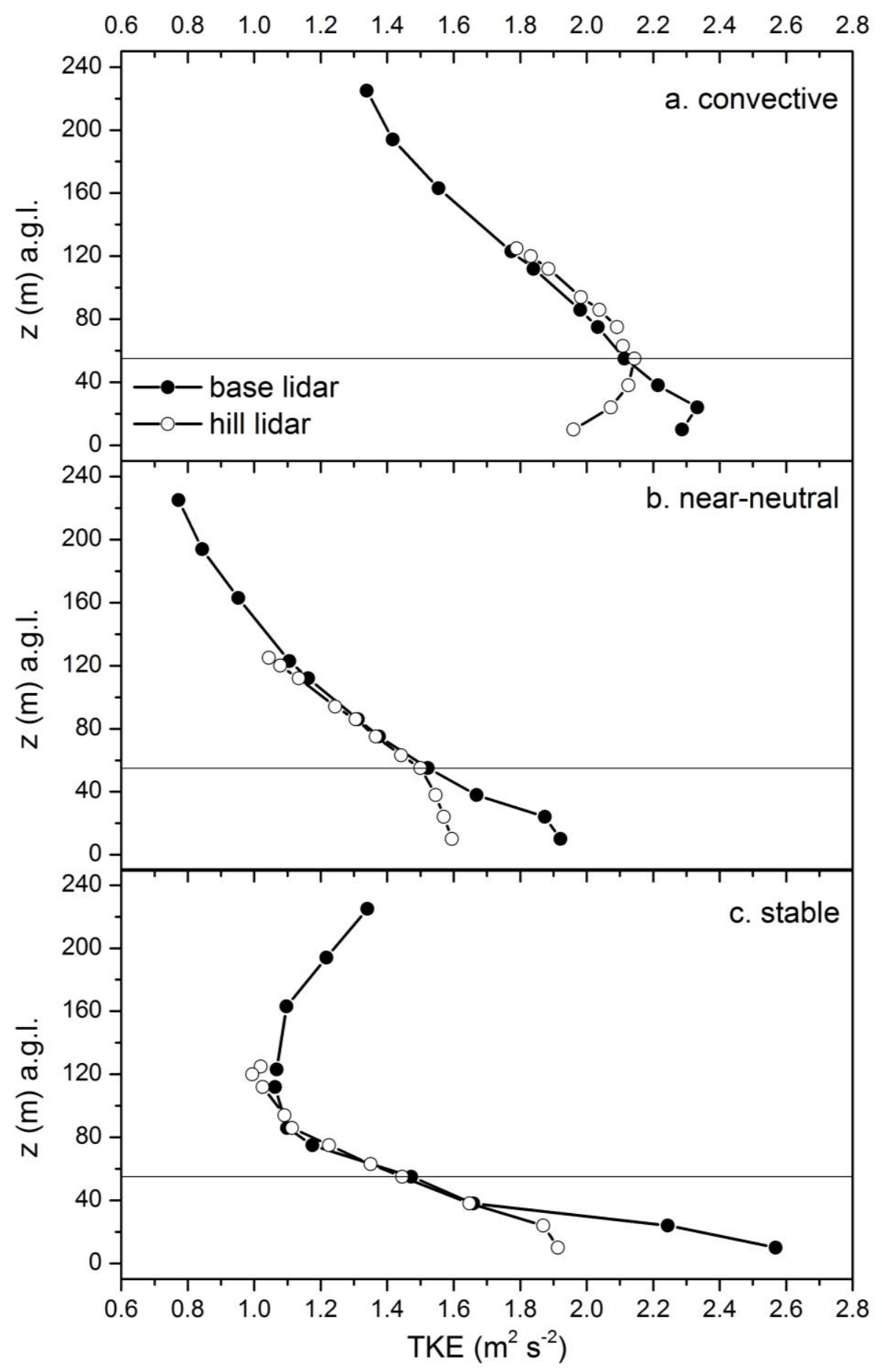

Figure 10: Mean turbulence kinetic energy (TKE) profiles for the base lidar and hill lidar depending on atmospheric stability. Turbine hub-height $(55 \mathrm{~m})$ is indicated with a drawn line. 


\subsection{Hill "speed-up" factors}

From the wind speed data, we calculated:

1. A "total-hill speed-up" defined as the difference between the nacelle wind speed (55 $\mathrm{m}$ a.g.l.) and the base lidar wind speed (55 $\mathrm{m}$ a.g.1.).

2. A "top-hill speed-up" defined as the difference between the nacelle wind speed (55 $\mathrm{m}$ a.g.1.) and the hill lidar wind speed (55 $\mathrm{m}$ a.g.1.)

3. A "mid-hill speed-up" defined as the difference between the hill lidar wind speed (55 m a.g.l.) and the base lidar wind speed (55 $\mathrm{m}$ a.g.l.)

Speed-up factor $(\Delta \mathrm{s})$ statistics are listed in Table 4 . A top-hill speed-up effect was evident in the observations and the degree of acceleration depended on atmospheric stability. The mean speedup factor $\left(\Delta \mathrm{s}_{\text {top-hill }}\right)$ between the hill lidar and turbine T08 was $0 \%$ during convective, $+3 \%$ during near-neutral, and $+4 \%$ during stable conditions. This indicates a small trend of increasing hill flow acceleration with increasing stability at the top portion of the ridge. The stability-related total-hill and mid-hill speed-up effects, however, were less straightforward. While the total-hill and mid-hill speed-up factors were higher during near-neutral conditions $\left(\Delta \mathrm{s}_{\text {total-hill }}=0.24\right.$ or $24 \%, \Delta \mathrm{s}_{\text {mid-hill }}=0.20$ or $\left.20 \%\right)$ than convective conditions $\left(\Delta \mathrm{s}_{\text {total-hill }}=0.15\right.$ or $15 \%, \Delta \mathrm{s}_{\text {mid-hill }}=$ 0.15 or $15 \%)$, they declined during stable conditions $\left(\Delta \mathrm{s}_{\text {total-hill }}=0.10\right.$ or $10 \%, \Delta \mathrm{s}_{\text {mid-hill }}=0.05$ or 5\%). In fact, mean wind speeds at the base of the hill approached speeds equal to those measured at the top of the ridge during stable conditions. These high wind speeds may be the 
result of strongly channeled flow through the 9-km canyon, which terminates at the base of the hill, as suggested by the wind roses in Figures $5 \mathrm{~b}$ and $5 \mathrm{e}$.

Table 4: Hill speed-up factor $(\Delta \mathrm{s})$ statistics by stability class and distance. Statistics include the mean, standard deviation $(\sigma)$, kurtosis $\left(\sigma^{3}\right)$, and maximum $\Delta \mathrm{s}$.

\begin{tabular}{|l|l|l|l|l|l|l|l|l|l|l|l|l|}
\hline & \multicolumn{4}{|c|}{ Stable } & \multicolumn{4}{c|}{ Near-Neutral } & \multicolumn{4}{c|}{ Convective } \\
\hline & Mean & $\sigma$ & $\sigma^{3}$ & Max & Mean & $\sigma$ & $\sigma^{3}$ & Max & Mean & $\sigma$ & $\sigma^{3}$ & Max \\
\hline Top hill $\Delta \mathrm{s}$ & 0.042 & 0.085 & 0.960 & 0.470 & 0.033 & 0.055 & -2.070 & 0.230 & 0.001 & 0.117 & -2.970 & 0.280 \\
\hline $\begin{array}{l}\text { Middle hill } \\
\Delta \mathrm{s}\end{array}$ & 0.045 & 0.239 & 0.850 & 0.970 & 0.198 & 0.124 & -0.749 & 0.540 & 0.153 & 0.125 & -0.090 & 0.620 \\
\hline Total hill $\Delta \mathrm{s}$ & 0.097 & 0.320 & 1.65 & 1.920 & 0.244 & 0.158 & -0.676 & 0.700 & 0.154 & 0.204 & -1.020 & 0.710 \\
\hline
\end{tabular}

As the top-hill $\Delta$ s appeared to be less influenced by upwind topography, this factor was chosen for further analysis on hill speed-up flows. Figure 11 shows the relationship between $\Delta \mathrm{s}$ and nacelle wind speed. At low wind speeds $(<6 \mathrm{~m} / \mathrm{s})$ the top-hill speed-up factors were largely negative indicating that the wind speed measured at the turbine nacelle was on average lower than the speed measured at the lower elevation by the hill lidar. The largest negative speed-up factors occurred at the lowest wind speeds which may suggest instrument measurement discrepancies at very low wind speeds, although the significance of this is largely offset by the fact that these occurred mostly below cut-in speed when the turbine is not producing power. The top-hill speed-up factor peaked, on average, for nacelle wind speeds around $9 \mathrm{~m} / \mathrm{s}$ and showed a $+5 \%$ increase in wind speed at the top of the hill. Beyond $12 \mathrm{~m} / \mathrm{s}$, the speed-up factors appear to slightly drop, which may coincide with neutral stability as the highest wind speeds are often 
associated with neutral conditions and we saw lower top-hill speed-up factors during near-neutral conditions than during stable. The speed-up factors increased for a second time for wind speeds beyond $19 \mathrm{~m} / \mathrm{s}$, however this rise is statistically uncertain as fewer data points are available at the highest wind speeds. The uncertainty in the speed-up factors beyond $12.5 \mathrm{~m} / \mathrm{s}$ (i.e., the rated wind speed) is also reduced in significance as this is the portion of the power curve where power is kept largely constant by adjusting the blade pitch angle and other turbine controls.

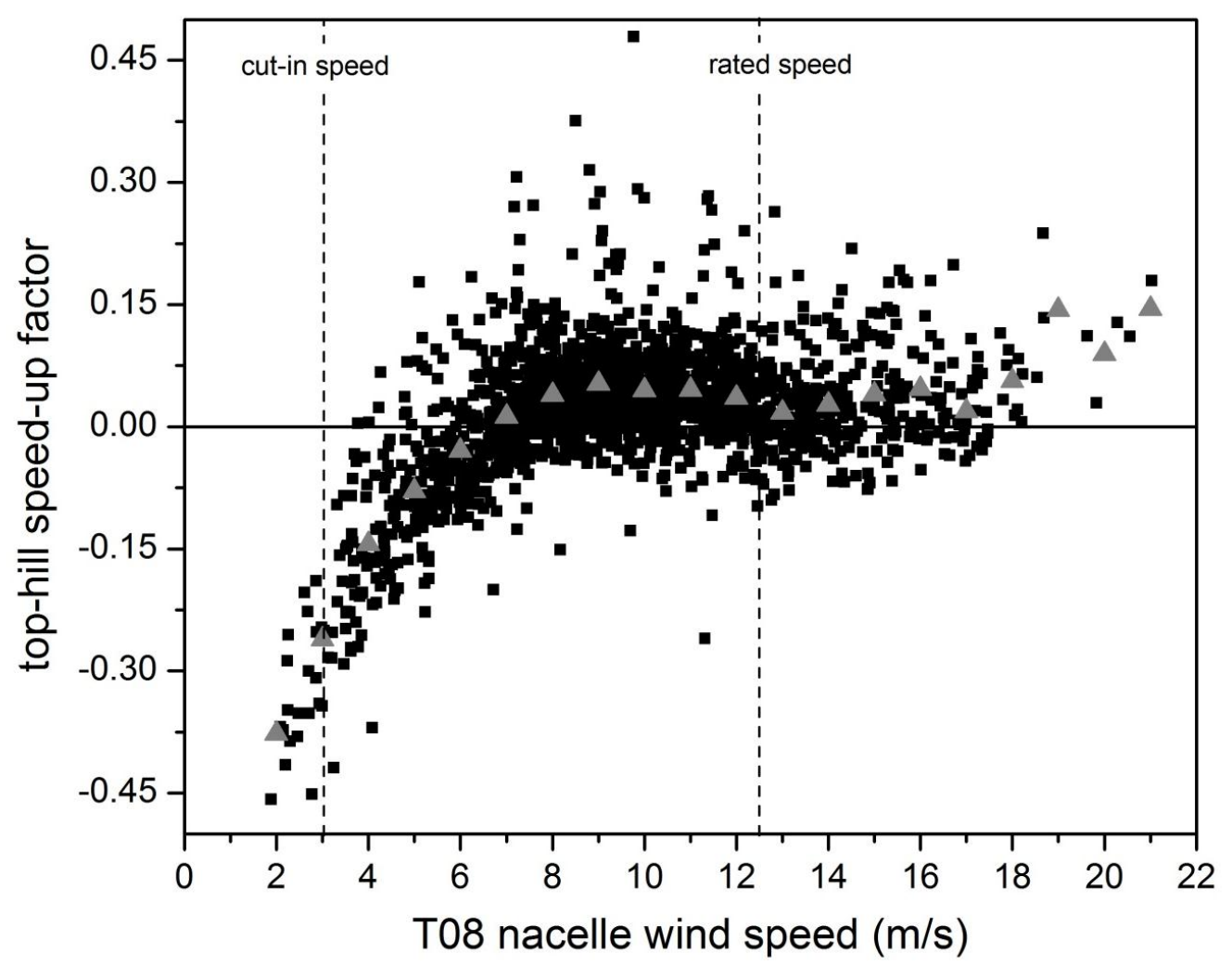

Figure 11: Top-hill speed-up factor $(\Delta s)$ as a function of nacelle wind speed for each 10-minute period. Mean $\Delta \mathrm{s}$ (gray triangles) are binned by wind speed. Turbine cut-in and rated speeds are also shown.

Mean wind speed profiles by stability class are shown in Figure 12 for both lidars in addition to the nacelle hub-height wind speed at T08 on the top of the ridge. Here, the data were filtered by 
nacelle wind speed so that only the $6-12.5 \mathrm{~m} / \mathrm{s}$ wind speed range was used. This was done (1) based on the $\Delta$ s results found in Figure 11, (2) to reduce a bias that is caused by the fact that a higher percentage of very low wind speeds are associated with convective conditions, and (3) because turbine power generation is most sensitive to small changes in wind speed over this range. The $6-12.5 \mathrm{~m} / \mathrm{s}$ range included $70 \%$ of available data. Figure 12 shows that both the wind speed magnitudes and shape of the wind profiles (i.e., wind shear) vary by stability class and lidar location. The shear exponent $(\alpha)$ ranged from 0.12 during convective conditions to 0.19 in stable conditions at the base lidar. Wind shear was lower overall at the hill lidar and $\alpha$ ranged from 0.0 in convective conditions to 0.12 during stable conditions. Figure 12 also clearly shows the behavior of the hill "speed-up" effect as a function of atmospheric stability. A total hill speed-up increases from convective to near-neutral conditions but behaves unexpectedly during stable conditions. This is due to very high wind speeds found at the base of the hill during stable conditions which are apparent in Figure 12c. 


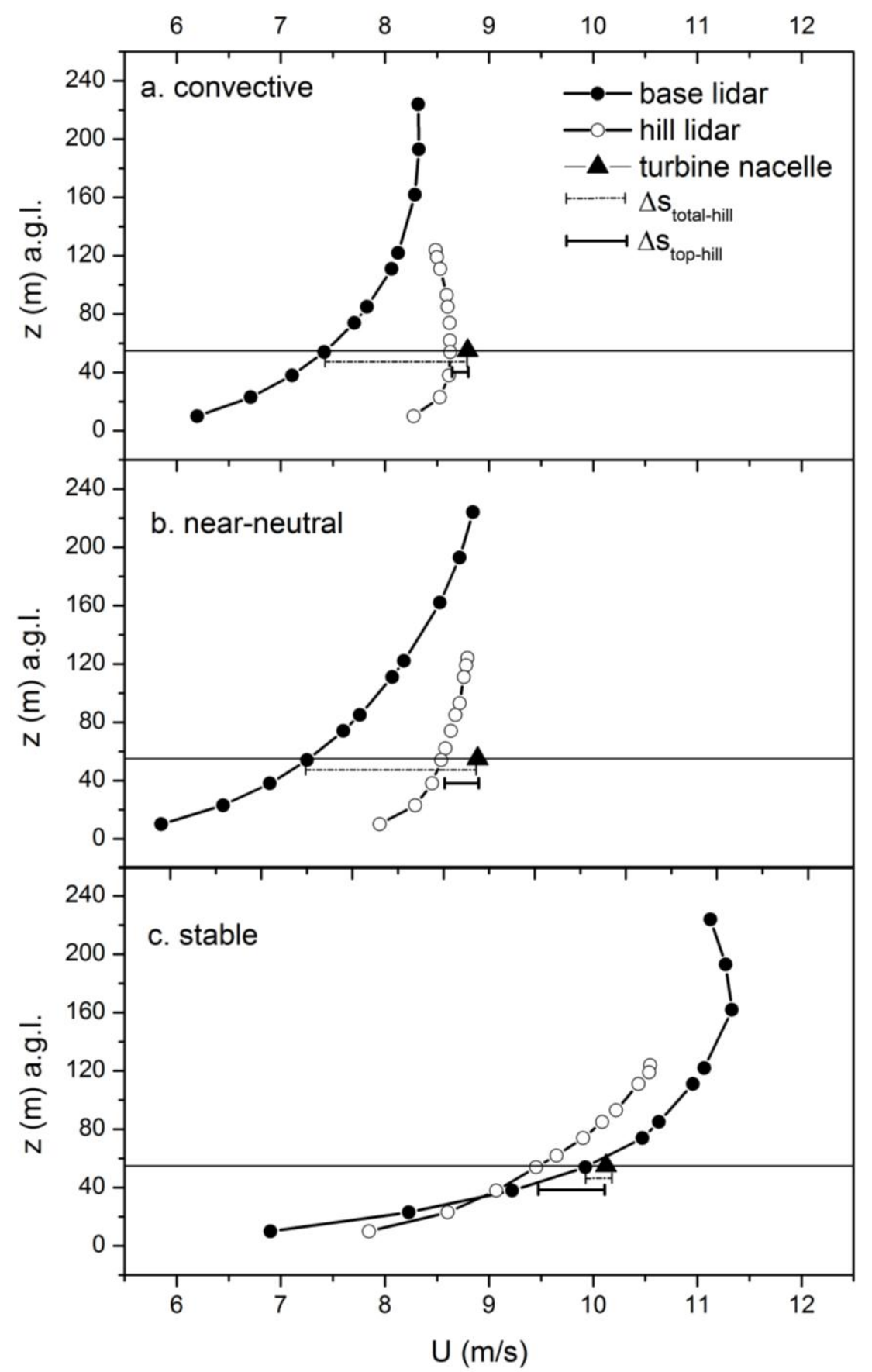

Figure 12: Mean wind speed (U) profiles for the base lidar and hill lidar depending on atmospheric stability for nacelle winds between $6-12.5 \mathrm{~m} / \mathrm{s}$. Also plotted is the mean nacelle wind speed from turbine T08. The small dashed and solid lines indicate the relative hill "speedup" for the total-hill and top-hill, respectively. Note the trend of increasing speed-up with increasing stability for the top-hill $\Delta \mathrm{s}$. Turbine hub-height is indicated with a drawn line at $55 \mathrm{~m}$. 


\subsection{Measured power curves}

The measured power curves shown in Figure 13 use the set of wind speed inputs defined in Section 4.4. Note that the wind speeds have been adjusted for deviations in air density from standard density $\left(\rho=1.225 \mathrm{~kg} / \mathrm{m}^{3}\right)$ as recommended by the IEC 61400-12 Standard (IEC 1998). This was done to generate comparisons between our measured power curves and the manufacture's power curve (MPC) which is based here on standard air density. The MPC is produced by the turbine manufacturer to illustrate expected turbine power response under ideal conditions (e.g., $\mathrm{TI}=10 \%$, flat ground, no flow distortion). In these curves, mean power is presented as a function of $0.5 \mathrm{~m} / \mathrm{s}$ wind bins. RMSEs (in MW) for the observed versus MPCexpected power responses are plotted in Figure 14 for the set of wind speed inputs during different wind speed ranges as defined in Section 4. 


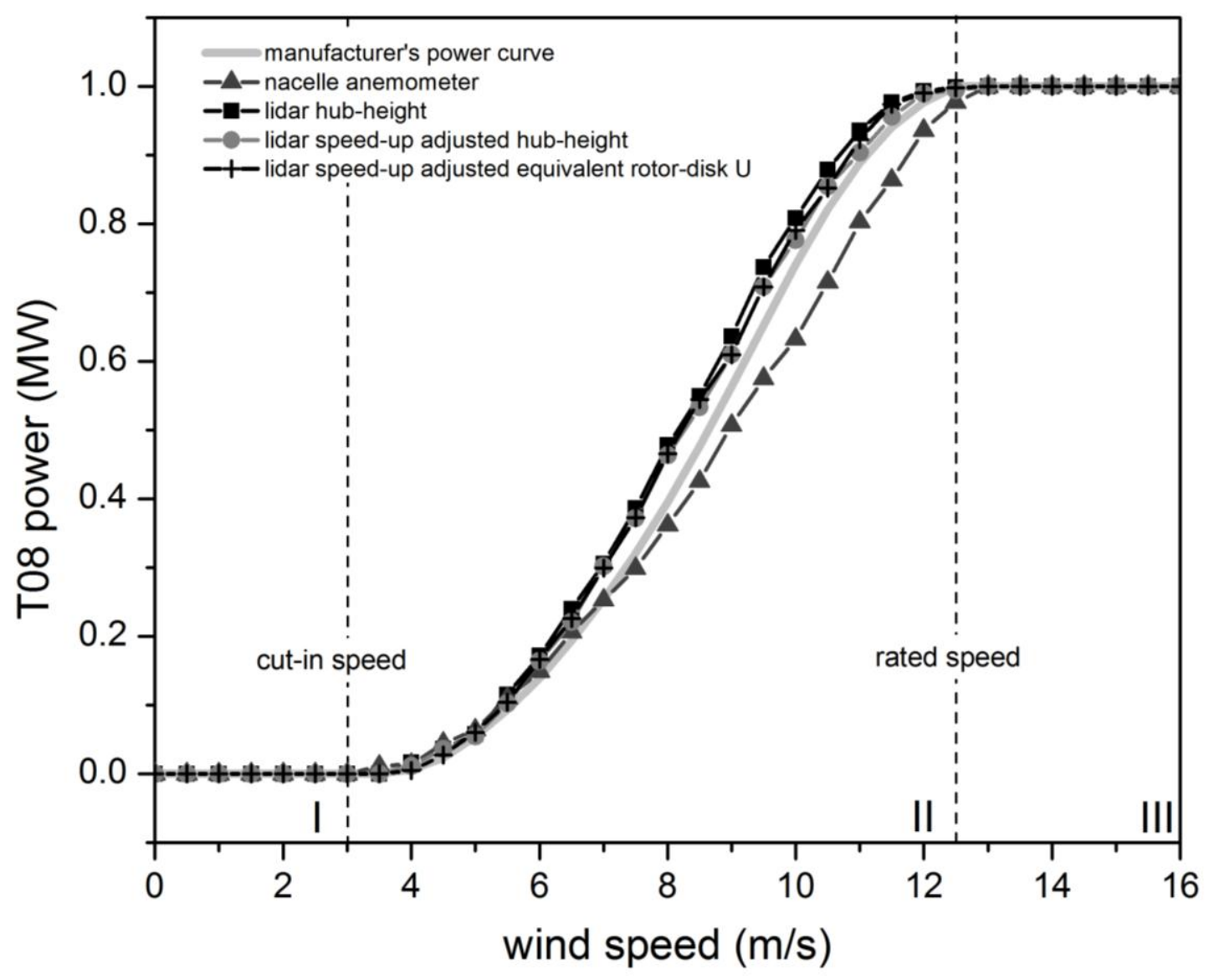

Figure 13: Measured power curves for turbine T08 based on the nacelle anemometer wind speed, lidar hub-height wind speed, speed-up adjusted lidar hub-height wind speed, and speed-up adjusted lidar equivalent rotor-disk wind speed. Measurements are plotted in comparison to the expected power based on the manufacturer's power curve (MPC). The Roman numerals indicate the three distinct regions in the power curve. Region III extends to $25 \mathrm{~m} / \mathrm{s}$ (not shown).

Observed power was largely lower than the MPC's estimated power when the nacelle wind speeds were used as input while the reverse was true for the lidar wind speeds (Figure 13). For example, turbine T08 produced less power than expected if the wind speed was based on the nacelle anemometer for moderate to high wind speeds $(9-12 \mathrm{~m} / \mathrm{s})$. Wind speeds in this range tended to correlate with stable or near-neutral conditions, large top-hill speed-up factors (mean $\Delta$ 
$=+4.5 \%$ ), and higher than average wind shear. The discrepancy may also be caused in part by the fact that cup anemometers are known to "overspeed" (Busch and Kristensen 1976) which would make the nacelle-generated power curve appear to under-predict the turbine's power response. Finally, the published MPC is based on TI values of $10 \%$ and may not represent the true power response for turbines in this area. Hub-height TI at this wind farm averages nearly $15 \%$.

In contrast, the lidar-generated power curve slightly over-predicted power as compared to the MPC within the same velocity range. The turbine is set at a higher elevation than the hill lidar and the wind speed at the lidar was on average $3 \%$ lower than at the top of the ridge for this wind speed range. Thus it would appear that the turbine generated more power for a given wind speed using the upwind lidar measurements. Once the lidar wind speeds were adjusted for observed top-hill speed-up effects, greater agreement (i.e., lower RMSE) with the MPC was reached (Figure 14). With the exception of the $6-9 \mathrm{~m} / \mathrm{s}$ range, little additional benefit was found from using the speed-up adjusted, rotor-disk equivalent wind speed instead of hub-height. This may be because wind shear is more variable closer to the surface than aloft in complex terrain and thus conditions found at the lidar may not accurately represent the conditions found at the bottom half of T08's rotor-disk. For this turbine, the benefits of using the lidar speed-up adjusted hub-height wind speed in lieu of the nacelle cup anemometer speed was greatest for the $9-12 \mathrm{~m} / \mathrm{s}$ wind class where RMSE was reduced by $3 \%$. This is a significant distinction for evaluating turbine performance or for predicting energy production given that 25 times more power is generated for the $9-12 \mathrm{~m} / \mathrm{s}$ wind class than for the $3-6 \mathrm{~m} / \mathrm{s}$ wind class. 


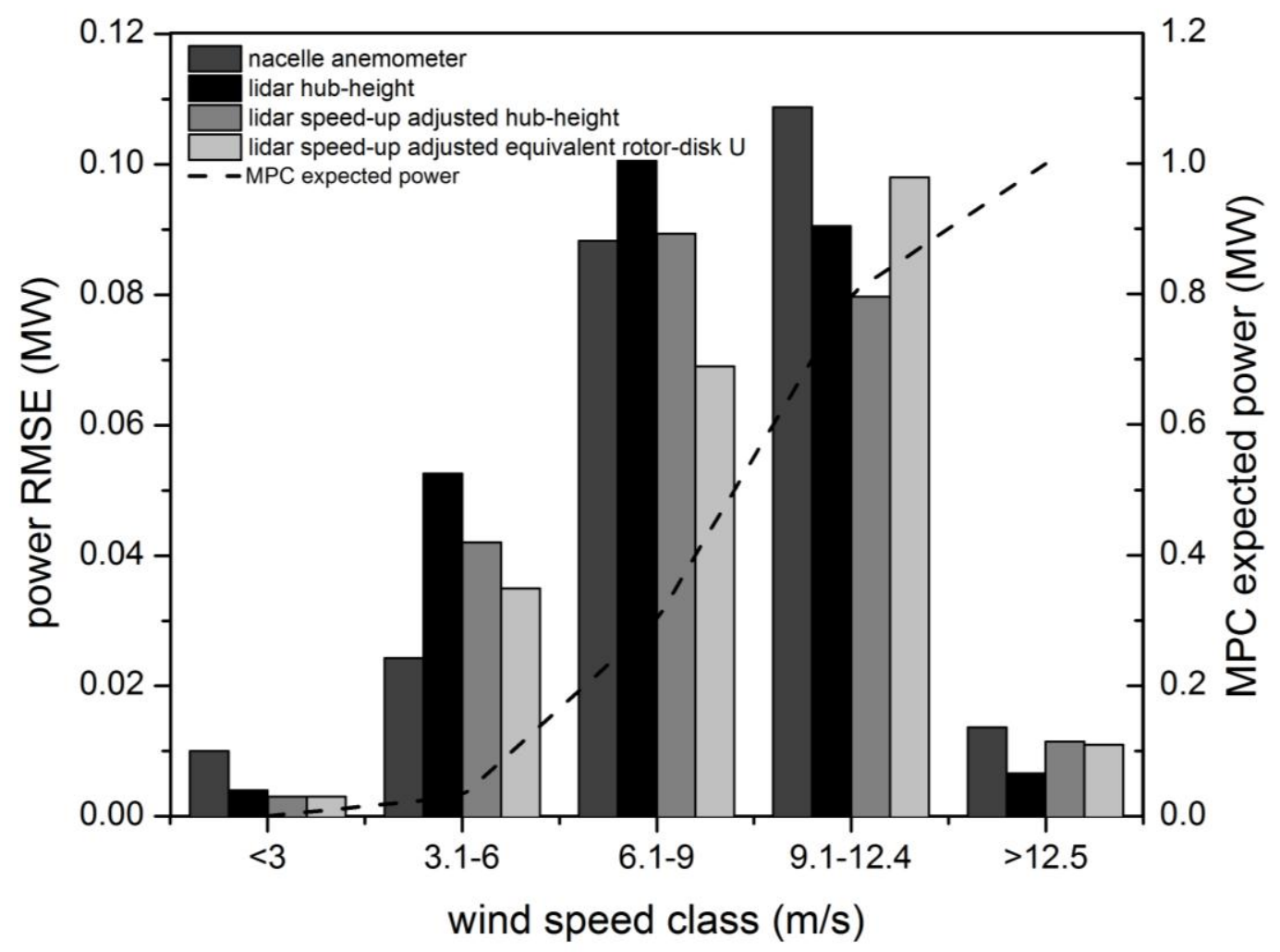

Figure 14: Mean RMSE (in MW) between T08 observed power and the expected power based on the manufacturer's power curve (MPC) for the set of four wind speed inputs and for different wind speed classes (bar graph, left axis). To put the error in perspective, also plotted is the expected power (in MW) for each wind speed class based on the MPC (dashed line, right axis).

\section{Discussion}

\subsection{Complex terrain effects on inflow}

Based on the linear theory of Hunt et al. 1988a the expected maximum speed-up on our ridgeline was around $77 \%$ during near-neutral conditions. This is very close to the observed value as our field data showed during near-neutral conditions a maximum total-hill speed-up of $70 \%$ at the top of the ridge. During stable conditions it was expected that the measured total-hill speed-up be even larger; however, our data did not indicate this. We did not see an increase in total-hill 
speed-up with increasing atmospheric stability. Instead, during stable conditions the winds at the base of the ridge were much higher than expected. This was likely due to the influence of two topographical features. Between 60-112 m a.g.l. and within the atmospheric middle layer the flow was heavily influenced by a nearby $9-\mathrm{km}$ long, $70 \mathrm{~m}$ deep canyon. This terrain feature likely channels and accelerated the flow found near the terminus at the base of the hill. Closer to the surface $(<20 \mathrm{~m})$ and within or just above the atmospheric inner layer the winds were distorted and re-directed by a $220 \mathrm{~m}$ tall upwind hill with mean slope of $13^{\circ}$. Furthermore, we saw no evidence of the upwind hill inducing a leeward flow separation at the base lidar. This is reasonable given that the upwind hill's slope is less than $20^{\circ}$ or the critical slope angle for steady separation for hills with low canopy roughness (Finnigan 1988).

The lack of a straightforward speed-up effect in stable conditions in addition to the unique flow features seen at the ridge base suggests that wind characteristics at the wind farm are far more complex than found in many earlier field studies (e.g. Mason and Sykes 1979, Sacré 1979, Bradley 1980, Taylor and Teunissen 1987, Mickle et al. 1988). Due to the uniqueness of topography and meteorology in the Altamont Pass, our findings are thus best compared to work in the same area by Nierenberg (1989). One of the instrumented wind farms in that earlier study, Souza Ranch, is similar to our experimental site; both lie near the terminus of a drainage canyon that is parallel to the prevailing wind direction. At Souza Ranch, Nierenberg (1989) observed speed-up factors ranging from 77-110\% using short upwind meteorological towers and wellinstrumented turbine nacelle cup anemometers at a hub-height of $11 \mathrm{~m}$. These speed-up factors are higher than we observed. This could be due to a lower measurement height in the earlier study as speed-up factors are expected to be highest in the atmospheric inner region (Coppin et 
al. 1994). In comparison, we estimated the depth of the inner region to be $17 \mathrm{~m}$ during nearneutral conditions at our site which would put our turbines well above this layer, particularly at night when the inner layer depth is expected to decrease. The turbines and nacelle measurements used in the Nierenberg (1989) study are shorter and likely resided, at least partially, within the inner layer where the maximum speed-up factors are expected to be found.

In agreement with our findings, Nierenberg (1989) also found significant flow distortions in the mean hub-height wind speed at Souza Ranch over small areas due to topography. These distortions, however, extend beyond changes in mean wind speed and flow inclination angle as profiles of wind shear, turbulence and direction are also influenced by terrain. The vertical resolution offered by lidar allowed for such an analysis in our study. The base and hill lidars were separated by a distance of $630 \mathrm{~m}$ and elevation of $100 \mathrm{~m}$. At the hill lidar we observed a higher flow inclination angle, lower wind shear (i.e., a more uniform wind speed profile with height), less wind veer (i.e., a more uniform wind direction profile with height), and less turbulence close to the ground than at the base of the ridge. An exception occurred during stable conditions when wind veer at the hill lidar was unusually large and indicated a counterclockwise rotation with decreasing height. If this veer is also present at the top of the ridge it could produce significant torque on the turbine blades which could result in significant fatigue loads on the turbine rotor. Unfortunately, veer measurements at the top of the ridge were not available for confirmation. 


\subsection{Power curve applications of the lidar-derived speed-up factor}

Unlike the total-hill speed-up observations, the top-hill speed-up factor behaved as expected for increasing stability. We used it to adjust the hill lidar measurements to "correct" for terraininduced differences between the upwind lidar and inflow conditions found at the top of the ridge. This was done to assess the sensitivity of the measured power curve to the choice of wind speed input. We found lower errors between the measured power curve and the expected turbine response based on the MPC power curve using the hill-speed up adjusted flow. This finding suggests that an upwind lidar in complex terrain can be used to approximate free stream, ridgeline flow if hill speed-up effects are taken into account. This finding has several advantages over relying on the nacelle wind speed. First, the lidar is measuring the free-stream wind while the nacelle anemometer is set behind the turbine blades and has significant flow interference from the rotation of the blades and structure of the nacelle. Second, the lidar additionally offers profiles of wind shear, veer and turbulence across the entire rotor disk. Shear, turbulence and other unsteady wind conditions have been shown to significantly affect turbine power response (e.g., van den Berg 2008, Antoniou et al. 2009, Wharton et al. 2012b, Clifton et al. 2013, Clifton and Wagner 2014, Bulaevskaya et al. 2015).

It must be noted that the complexity of the terrain at the studied wind farm introduces instrument error for both the cup anemometer and lidar which translates to uncertainty in our reported power curve responses. Error is introduced in the following ways. First, the ZephIR 300 lidar measures the radial velocity using a circular pattern scan with a cone half-angle of $30^{\circ}$. Horizontal wind speed is derived from this measurement using an assumption that the flow is homogenous within the scanned area. Because complex terrain introduces the likelihood of heterogeneous flow, 
errors are introduced in the derived wind speed measurement which can approach 10\% (Pitter et al. 2012). These errors were mitigated here using the Dynamics software which corrects the horizontal wind speeds based on CFD modeled airflow simulations to derive site-, direction-, and height-specific correction factors. Cup anemometer instruments are also prone to errors in complex terrain. Changes in the air flow (e.g., increased turbulence, large flow inclination angles) induced by terrain features and the placement of the instrument behind the rotating turbine blades increases error in the cup anemometer measurements by 5-10\% (Papadopoulos et al. 2001).

Additionally, error in the expected turbine power response is introduced by the flow inclination angle at the top of the hill which creates an inflow angle or deviation of the directional component of the wind speed from the turbine rotor axis in the vertical plane. Wind turbines are certified for inflow angles usually within $\pm 8^{\circ}$ as required by the IEC $61400-1$ Standard. We observed upslope flows approaching $8^{\circ}$ with the hill lidar near the top of the ridge so it is possible that significant inflow angles are at times experienced at the top of the ridge by turbine T08. Although the inflow angle at the crest of the ridge is likely less than what was observed with the hill lidar, this angle, if significant, would likely lessen actual power output at T08 as compared to the expected power based on the manufacturer's power curve.

\subsection{Recommended practices for future campaigns}

Since the nacelle anemometer likely underestimates wind speed because of waking from the blades, it's possible that the speed-up effect is even more prominent than measured during our experiment. Future experiments would be improved by scheduling downtime of the turbines 
which would allow the measurement of free-stream inflow at the top of the ridge using a verticalprofiling lidar. Stopping operation of the turbine blades would also allow for a more accurate measurement of free-stream wind speed from a nacelle-mounted cup anemometer. Lastly, it is recommended that future experiments obtain a precise measurement of atmospheric stability from either an on-site calculation of the Obukhov length or Richardson number so that a more detailed stability analysis can be made.

\section{Conclusions}

From our findings we conclude that:

1. Vertically-profiling lidars can be used in complex terrain to measure turbine inflow conditions if the wind speeds are carefully adjusted for site-specific topography. Given that lidars offer a suite of measurements across the entire rotor disk, this finding is promising for a number of wind power applications including turbine sitting and for determining causes for turbine underperformance.

2. Inflow conditions near the top of a non-isolated, 140-m tall, low canopy roughness ridge were associated with less wind shear, wind veer, and turbulence than at the base of the hill at this wind farm.

3. An accelerated hill flow or a wind "speed-up" was consistently observed for the top quarter of the ridge. This "speed-up" was related to atmospheric stability and increased with increasing stability. 
4. A hill "speed-up" phenomena at the Altamont Pass Wind farm is far more complex than predicted by other field campaigns (e.g., Askervein Hill; Taylor and Teunissen 1987, Mickle et al. 1988), wind tunnel studies (e.g., Teunissen et al. 1987), or numerical models (e.g., Beljaars et al. 1987) of an isolated hill. Therefore, the results from our study are more applicable to other studied wind resource areas in complex terrain, including those in the Western U.S. (e.g., Sharp and Mass 2004, Smith et al. 2014).

\section{Acknowledgements}

The authors would like to thank Bryan Maddox (Infigen Energy) and Jeff Mirocha, Cary Gellner and John van Fossen (LLNL) for their assistance with the lidar deployments. Additionally, we'd like to thank Dave Carlson (Campbell Scientific) and Tony Rutherford (Zephir Ltd.) for providing guidance on operating the ZephIR 300 lidar and Edward Burin des Roziers (Zephir Ltd.) for running the VENTOS CFD model. This research was supported by a Laboratory Directed Research and Development (LDRD) award (12-ERD-069). Lawrence Livermore National Laboratory is operated by Lawrence Livermore National Security, LLC, for the US Department of Energy, National Nuclear Security Administration under Contract DE-AC5207NA27344. LLNL-JRNL-660148

\section{References}

Antoniou, I., S.M. Pedersen, and P.B. Enevoldsen, 2009: Wind shear and uncertainties in power curve measurements and wind resources. Wind Engineering, 33, 449-468 
Arya, S.P.S., M.E. Capuano, and L.C. Fagen, 1987: Some fluid modelling studies of flow and dispersion over two-dimensional low hills. Atmos. Environ., 21, 753-764

Beljaars, A.C.M., J.L. Walmsley, and P.A. Taylor, 1987: Modelling of turbulence over low hills and varying surface roughness. Boundary-Layer Meteorol., 41, 203-215

Bleeg, J., D. Dnyanesh, J. Woodcock and J.-F. Corbett, 2015: Modeling stable thermal stratification and its impact on wind flow over topography. Wind Energy, 18, 369-383 Bingöl, F., J. Mann, and D. Foussekis, 2009: Conically scanning lidar error in complex terrain. Met. Zeitschrift, 18, 189-195

Bradley, E.F., 1980: An experimental study of the profile of wind speed, shearing stress and turbulence at the crest of a large hill. Quart. J. Roy. Meteorol. Soc., 106, 101-124

Bulaevskaya, V, S. Wharton, A. Clifton, G. Qualley, and W. Miller, 2015: Power curve modeling in complex terrain using statistical models. J Renewable Sustainable Energy, 7, 013103: doi:10.1063/1.4904430

Busch, N.E. and L. Kristensen, 1976: Cup anemometer overspeeding. J Appl. Meteor., 15, 13281332

Cao, S. and T. Tamura, 2006: Experimental study on roughness effects on turbulent boundary layer flow over a two dimensional steep hill. J Wind Engin. Industr. Aerodyn., 94, 1-19 Clifton, A., L. Kilcher, J.K. Lundquist, and P. Fleming, 2013: Using machine learning to predict wind power output. Environmental Research Letters, 8, 024009

Clifton, A. and R. Wagner, 2014: Accounting for the effect of turbulence on wind turbine power curves. J Physics: The Science of Making Torque from Wind 2014 Conference Series, 524, 012109: doi: 0.1088/1742-6596/524/1/012109 
Coppin, P.A., E.F. Bradley, and J.J. Finnigan, 1994: Measurements of flow over an elongated ridge and its thermal stability dependence: the mean field. Boundary-Layer Meteor. 69, 173-199 Finnigan, J.J., 1988: Air flow over complex terrain. In Steffen, W.L. and O.T. Denmead (eds.) Flow and Transport in the Natural Environment: Advances and Applications, Springer-Verlag, Heidelberg, 183-229 p.

Finnigan, J.J, M.R. Raupach, E.F. Bradley, and G.K. Aldis, 1990: A wind tunnel study of turbulent flow over a two-dimensional ridge. Boundary-Layer Meteorol., 50, 277-317

Hunt, J.C.R., S. Leibovich, and K.J. Richards, 1988a: Turbulent shear flows over low hills, Quart. J. Roy. Met. Soc., 114, 1435-1470

Hunt, J.C.R., K.J. Richards, and P.W.M. Brighton, 1988b: Stably stratified shear flow over low hills, Quart. J. Roy. Meteorol. Soc., 114, 859-886

Jackson, P. S. and J.C.R. Hunt, 1975: Turbulent wind flow over a low hill, Quart. J. Roy. Meteorol. Soc., 101, 929-955

Kaimal, J.C and J.J. Finnigan, 1994: Atmospheric Boundary Layer Flows: Their Structure and Measurement, Oxford University Press, Oxford, England, 285 p.

Imamura, H., T. Tsumanuma, J. Kurokawa, and H. Katsuchi, 2003: Wind Tunnel Investigation of Flow over Various Escarpment Shapes. Proc. $7^{\text {th }}$ Asian International Conference on Fluid Machinery, 7-10 October 2003, Fukuoka, Japan, 6 p.

International Energy Agency (IEA), 2013: Wind Expert Group Study of Recommended Practices: 15. Ground-based, Vertically-Profiling Remote Sensing for Wind Resource Assessment. Eds. Andy Clifton and Dennis Elliot, First edition, 55p International Electrotechnical Commission (IEC), 1998: 61400-12 Ed. 1: Part 12: Wind Turbine Power Performance Testing, IEC: Geneva, Switzerland, $50 \mathrm{p}$. 
International Electrotechnical Commission (IEC), 2007: 61400-12-1 Ed. 1: Part 12-1: Power Performance Measurements of Electricity Producing Wind Turbines; IEC: Geneva, Switzerland Lemelin, D.R., D. Surry, and A.G. Davenport, 1988: Simple approximations for wind speed-up over hills. J Wind Engin. Indusrial. Aerodyn., 28, 117-127

Mann, J., S. Ott, B.H. Jørgensen, and H.P. Frank, 2002: WAsP Engineering 2000, Technical Report R-1356(EN), Risø National Laboratory

Mason, P.J. and R.I. Sykes, 1979: Flow over an isolated hill of moderate slope. Quart. J. Roy. Meteorol. Soc., 105, 383-395

Mickle, R.E., N.J. Cook, A.M. Nott, N.-O. Jensen, J.R. Salmon, P.A. Taylor, G. Tetzlaff, and H.W. Teunissen, 1988: The Askervein Hill Project: vertical profiles of wind and turbulence. Boundary-Layer Meteorol., 43, 143-169

Nierenberg, R., 1989: Free-flow variability on the Jess and Souza Ranches, Altamont Pass. SERI/STR-217-3404, DE89000889, 144 p.

Panofsky, H.A., and Z. Ming, 1983: Characteristics of wind profiles over complex terrain. J Wind Engineering and Industrial Aerodynamics, 15, 177-183

Pitter, M., C. Abiven, K. Vogstad, M. Harris, W. Barker, and O. Brady, 2012: Lidar and computational fluid dynamics for resource assessment in complex terrain. Proc. 2012 European Wind Energy Association Conference and Exhibition, Copenhagen, Denmark, 10p Papadopoulos, K.H., Stefanatos, N.C., Paulsen, U.S., Morfiadakis, E., 2001. Effects of turbulence and flow inclination on the performance of cup anemometers in the field. BoundaryLayer Meteorology, 101, 77-107.

Sacré, C., 1979: An experimental study of the airflow over a hill in the atmospheric boundary layer. Boundary Layer Meteor., 17, 381-401 
Sharp, J., and C.F. Mass, 2004: Columbia Gorge gap winds: their climatological influence and synoptic evolution. Weather and Forecasting, 19, 970-992

Slinger, C. and M. Harris, 2012: Introduction to Continuous-Wave Doppler Lidar. Proc. Summer School in Remote Sensing for Wind Energy, 11-15 June 2012, 32 p.

Smith, C., D. Koracin, and K. Horvath, 2014: Day-ahead predictability of complex terrain flows for wind resource production: a case study of the Washoe Zephyr. Wea. Forecasting, 29, 13431355

Stull, R.B., 1988: An Introduction to Boundary Layer Meteorology. Kluwer Academic Publishers, Boston, MA, 670 p.

Takahashi, T., S. Kato, S. Murakami, R. Ooka, M,. Yassinc Mohamed Fassy, and R. Kono, 2005: Wind tunnel tests of effects of atmospheric stability on turbulent flow over a threedimensional hill. $J$ Wind Enginer. Industr. Aerodyn., 93, 155-169

Taylor, P.A., P.J. Mason, and E.F. Bradley, 1987: Boundary-layer flow over low hills. Boundary-Layer Meteorol., 39, 107-132

Taylor, P.A. and H.W. Teunissen, 1987: The Askervein Hill Project: overview and background data. Boundary-Layer Meteorol., 39, 15-39

Teunissen, H.W., M.E. Shokr, A.J. Bowen, C.J. Wood and D.W.R. Green, 1987: The Askervein Hill Project: wind-tunnel simulations at three length scales. Boundary-Layer Meteorol., 40, 1-29 van den Berg, G.P., 2008: Wind turbine power and sound in relation to atmospheric stability. Wind Energy, 11, 151-169 
Wagner, R., I. Antoniou, S.M. Pedersen, M.S. Courtney, and H.E. Jørgensen, 2009: The influence of the wind speed profile on wind turbine performance measurements. Wind Energy, 12, 348-362

Weng, W., P.A. Taylor, P.A. and J.L. Walmsley, J.L., 2000: Guidelines for airflow over complex terrain: model developments, Journal of Wind Engineering and Industrial Aerodynamics, 86, 169186

Wharton, S. and J.K. Lundquist, 2012a: Assessing atmospheric stability and its impacts on rotordisk wind characteristics at an onshore wind farm. Wind Energy, 15, 525-546

Wharton, S. and J.K. Lundquist, 2012b: Atmospheric stability affects wind turbine power collection. Environmental Research Letters, 7, doi:10.1088/1748-936/7/1/014005 